\title{
La influencia de la ilustración en la contabilidad del convento de Los Llanos (1718-1789)
}

\author{
María del Mar López Pérez ${ }^{a}$, Ángel Tejada Ponce ${ }^{b}$
}

a) Departamento de Economía Española e Internacional, Econometría e Historia e Instituciones Económicas, Facultad de Ciencias Económicas y Empresariales, Universidad de Castilla-La Mancha, Albacete, Spain.

b) Departamento de Administración de Empresas, Facultad de Ciencias Económicas y Empresariales, Universidad de Castilla-La Mancha, Albacete, Spain.

\begin{tabular}{|c|c|}
\hline A R T I C L IN F O & R E S U M E N \\
\hline $\begin{array}{l}\text { Article history: } \\
\text { Received 17 May } 2019 \\
\text { Accepted } 3 \text { May } 2020 \\
\text { Available online } 1 \text { July } 2021\end{array}$ & $\begin{array}{l}\text { Este artículo pretende poner de manifiesto la influencia del movimiento ilustrado en la contabilidad de } \\
\text { una institución religiosa y cómo, a partir de la misma, se puede explicar la adaptación de dicha institución } \\
\text { para hacerse eco de las transformaciones económicas impulsadas por las corrientes ideológicas que dejan } \\
\text { su impacto en las decisiones de actuación. }\end{array}$ \\
\hline $\begin{array}{l}\text { Códigos JEL: } \\
\text { M410 } \\
\text { N330 }\end{array}$ & $\begin{array}{l}\text { de su sistema contable, con un sistema de rendición de cuentas más preciso, supuso una adaptación a las } \\
\text { dificultades económicas del siglo XVIII que llegaron con una influencia del movimiento ilustrado en España. }\end{array}$ \\
\hline & $\begin{array}{l}\text { (C)2021 ASEPUC. Published by EDITUM - Universidad de Murcia. This is an open access article under the } \\
\text { CC BY-NC-ND license (http://creativecommons.org/licenses/by-nc-nd/4.0/). }\end{array}$ \\
\hline
\end{tabular}

Palabras clave:

Cargo y data

Organizaciones religiosas

Historia y contabilidad

Análisis documental

The influence of enlightenment on accounting in the convent of Los Llanos (17181789)

A B S T R A C T

JEL classification:

M410

N330

Keywords:

Single-entry Accounting

Religious organizations

History and Accounting

Documentary analysis
This article aims to highlight the influence of the Enlightenment movement on the accounting of a religious institution and how, on the basis of this, it is possible to explain the adaptation of this institution to take on the economic transformations driven by ideological currents that leave their impact on decisions to act. In this context, the decisions regarding the increase of commercialization and the consequent adaptation of its accounting system, with a more precise accountability system, meant an adaptation to the economic difficulties of the $18^{\text {th }}$ century that came with an influence of the Enlightenment in Spain.

(C)2021 ASEPUC. Publicado por EDITUM - Universidad de Murcia. Este es un artículo Open Access bajo la licencia CC BY-NC-ND (http://creativecommons.org/licenses/by-nc-nd/4.0/). 


\section{Introducción}

El objetivo de este trabajo es doble. Por una parte, analizar el sistema contable de una institución religiosa castellana, Convento de Los Llanos de la villa de Albacete, perteneciente a la orden franciscana y, por otra, a partir de su contabilidad, reconstruir los flujos de efectivo generados por la actividad económica de esta institución en la mayor parte del siglo XVIII, e integrarla en su entorno económico y social. El estudio se inicia en el año 1718, desde cuando existen registros en los libros de cuentas y se extiende hasta 1789 , este último con registros incompletos de solo unos meses.

Los registros contables de las instituciones religiosas, en línea con lo señalado por (Maté et al., 2017), son un elemento clave para comprender las actividades económicas y sociales desempeñadas en un determinado contexto geográfico y temporal. En este sentido, el estudio de la contabilidad supone una importante contribución a la historia económica y social.

Las investigaciones sobre historia de la contabilidad giran en torno a dos grandes corrientes que se discuten y confrontan en la disciplina: contabilidad histórica tradicional y moderna historia de la contabilidad (Napier, 2006). Siendo destacable en ambas la expresión de los cambios contables producidos en las diferentes épocas, pero difiriendo el tratamiento de estos, predominando más en la primera un punto de vista descriptivo que, sin embargo, no elude incidir en las causas y efectos y, en la segunda, un enfoque interdisciplinar que trata de sustentar y explicar los cambios sobre la base de modernas teorías organizativas y sociológicas (Lillo \& Álvarez, 2006).

Concretamente, el contexto de este trabajo se enmarca en los estudios de los sistemas contables de las entidades conventuales y pretende describir el sistema contable y, en su caso, su evolución a lo largo del siglo XVIII, además de utilizar dicho sistema para analizar las operaciones económicas registradas por el Convento y su incidencia en la vida económica y social del entorno que ubicaba dicho Convento. En este sentido, se pretende analizar si se produjo alguna influencia de las corrientes sociales y económicas de la época en la contabilidad del Convento. Además, teniendo en cuenta que durante la segunda mitad del siglo XVIII los principios de la Ilustración estaban difundiéndose en España, se ha intentado estudiar, a partir de los datos contables, en qué medida ello influyó en las actividades del convento, incentivando actividades comerciales y financieras, incluso suponiendo una contradicción con el recogimiento que implicaba la pertenencia a la orden que regía el Convento y, en qué medida, estas actividades motivaron alguna modificación en el sistema contable aplicado.

La información, desde el punto de vista contable, de las instituciones eclesiásticas empieza a ser abundante en los últimos años, abordada por historiadores de la contabilidad. Los estudios iniciados desde la historia económica, tal y como afirma Hernández Esteve (Rivero et al., 2005), incluyen un análisis de la práctica contable de estas instituciones.

El sistema contable de otras instituciones eclesiásticas del Antiguo Régimen se incorpora a los estudios. Así, se dispone de este análisis para las catedrales de Sevilla (Hernández Borreguero, 2002) y Toledo (Villaluenga, 2004). Se analizan, además otras entidades menores como las Capillas de San Andrés de Cádiz y de Jaén (Lillo \& Álvarez, 2006), capellanías y casas de hermandades. Se ha investigado también acerca de la diócesis de Canarias (Calvo, 1999). De otras instituciones se ha examinado la información contable que proporcionan sus libros de cuentas, en particular de hospitales, como el de Santa Cruz de Toledo (Jiménez \& Villaluenga, 2000), el de
San Julián de Albacete (López \& Pérez, 2007), el de Santa Marta de Sevilla (Hernández, 2008) o el de la Caridad de La Coruña (Salvador \& Ruiz, 2011). Centrándonos en los estudios de contabilidad conventual, fueron dos las publicaciones pioneras: la del Convento, también franciscano, de Cuevas de Almanzora en Almería (Pezzi, 1994) y los diversos análisis del Monasterio de Santo Domingo de Silos (Maté et al., 2004). Además, destacan los del Monasterio de Santa María la Real de Oseira (Rivero et al., 2005) y el Monasterio de Guadalupe (Llopis, 1995). En el trabajo realizado por Maté, Prieto y Santidrián (Maté et al., 2017) se recogen de forma sintética las aportaciones sobre la contabilidad monástica en las edades medieval y moderna, incidiendo en el gobierno de estas instituciones, en el control y rendición de cuentas, así como en la toma de decisiones de estas entidades.

Para el estudio contable del Convento de Nuestra Señora de los Llanos, se dispone de sus libros de cuentas, donde se informa del estado de la Cuenta general. Se observa que la práctica contable del Convento se basó en el sistema de cargo y data, a pesar de que en las fechas analizadas se estaba empleando la partida doble. Esta forma de llevanza de la contabilidad es similar con lo que se hacía en las haciendas agrícolas en la que, además de los cobros y pagos, figuraba como saldo el dinero que quedaba en manos del Síndico. La contabilidad servía como mecanismo de control de modo que era posible la administración del convento y el seguimiento de la regla franciscana.

La primera parte de este trabajo se basa en la descripción e interpretación del modelo contable, además de exponer la organización en materia de control económico. En segundo lugar, se analizan las prácticas contables y si su evolución estuvo vinculada a las nuevas corrientes sociales, económicas y culturales extendidas en España sobre todo a partir de la segunda mitad de siglo. A continuación, se estudian los ingresos de la institución que, como se verá, a pesar de ser una institución franciscana, estuvieron basados, sobre todo a partir de la segunda mitad de siglo, en las ventas de víveres, textiles y ganados, así como por donativos que particulares otorgaban de forma desinteresada, aparte de las labores propias de la actividad religiosa (misas). Por último, el análisis de los gastos ha llevado a distinguir aquellos procedentes del mantenimiento de la comunidad, los de mayor cuantía y regularidad, los de personal, los de conservación del patrimonio y las obligaciones tributarias.

\section{Cuentas del Convento de Los Llanos en el siglo XVIII}

El Convento de los Llanos fue fundado bajo la advocación de los franciscanos en 1672 según los primeros documentos del propio Convento (Carrión, 2006, págs. 167-258). Los frailes franciscanos tomaron posesión de la ermita existente en el paraje de Los Llanos, construida con las limosnas y donativos de los habitantes de la villa de Albacete para la devoción de la Virgen de los Llanos, tras la firma de un acuerdo entre el concejo de Albacete y el superior de la orden franciscana de Valencia, a quien correspondía la gestión de esta zona ( $\mathrm{Ca}-$ rrión, 2010).

El convento de los Llanos estaba ubicado entre las localidades de Chinchilla de Montearagón y la villa de Albacete, junto al camino real que comunicaba ambas villas, y junto al que se encontraba una venta para atención de los peregrinos. Disponía de un recinto con las zonas de utilización de los ganados, además del huerto que servía para una parte del mantenimiento de la comunidad eclesiástica. Debían ser de dominio de la comunidad eclesiástica algunas tierras que rodeaban al convento, perdidas en el año 1835 por el proceso 
de desamortización.

La orden de los franciscanos se gobernaba por la Regla aprobada en 1223, a partir de la cual se hicieron sucesivas ampliaciones. Es un documento de carácter jurídico que expresa los principios generales por los que se ha de regir la comunidad (Ghinato, 1975). Recoge las normas eclesiásticas que deben seguir quienes siguen los principios de la orden, como la impartición de misas, manteniéndose la máxima de la austeridad, que debía dominar sobre cualquier otra norma. Se concretaban en ellas también las instrucciones para la administración y gestión de sus bienes, que son las que nos interesan en el análisis del sistema contable desarrollado por esta institución.

\subsection{Agentes del Convento}

Los principales agentes vinculados con la gestión del Convento de acuerdo con las Regla que gobernaba la orden de los franciscanos y conforme a lo registrado en los libros de cuentas del Convento eran el Definitorio, el Comisario Visitador, el Guardián y el Síndico, como puede observarse en la figura 1 .

Figura 1

Estructura organizativa del convento (1718-1789)

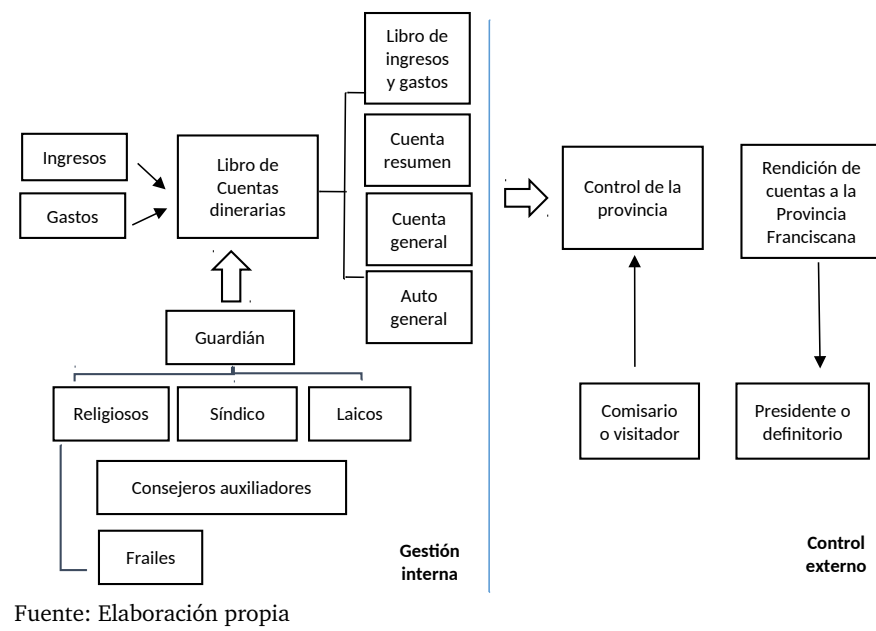

La máxima autoridad para la gestión de la Congregación era el Definitorio o Presidente. Su labor era mantener la regla y constitución de la orden, garantizando la vida espiritual y material del Convento. En el ámbito que nos ocupa en este trabajo, una de sus funciones, reflejada en el Libro de Misas, era la autorización para celebrar un número determinado de éstas, el cual no podía ser sobrepasado por los sacerdotes. Por este motivo cada uno de ellos debía firmar las misas rezadas o cantadas y restarlas del total autorizado. En caso de que fuese necesario impartir un número mayor por necesidades de mantenimiento de la comunidad, el definitorio podía aprobar la impartición de un número extraordinario de ellas.

La tarea principal del Comisario Visitador era velar por el cumplimiento de las obligaciones religiosas y eclesiásticas, entre ellas la buena administración de los bienes de la Comunidad. Para ello, su función era controlar, con una periodicidad variable, el libro de cuentas y hallar ajustadas las cuentas de entradas y salidas, tanto del Libro de Cuentas pecuniarias como del Libro de Cuentas dinerarias. Fue general que hallase conformidad en cómo eran llevadas. Sin embargo, hubo veces en que contaba con entradas en azafrán que no se habían declarado, por lo que solicitaba al guardián que actuase "con legalidad, las reglas y constituciones de la orden" (AHN, Clero, libro 24)
El guardián era el prelado ordinario, es decir, la máxima autoridad del Convento. Estaba encargado de anotar y controlar las provisiones en especie. Debía llevar cuenta de ellas y razonar los motivos que justificaban los gastos. Asimismo, debía dar fe de las cuentas-resumen realizadas por el síndico en el Libro de Cuentas dinerarias, que debía firmar al anotarse cada uno de los alcances.

El encargado de la Tesorería era el Síndico. Se trataba de un funcionario seglar cuya misión original consistía en recoger el dinero de las limosnas a los religiosos mendicantes, que separaban así en cierta medida el comercio con la vida material. Actuaba como Administrador General y era quien debía apuntar las entradas y salidas en dinero. Asimismo, debía guardar los fondos excedentarios, o bien prestar al Convento en caso de ajuste negativo. Era la única persona ajena a la Orden franciscana que tenía acceso a las cuentas de la Comunidad.

Por último, participaban en la administración y control de cuentas del Convento otros hermanos de la congregación. Su función era la de consejeros auxiliadores tanto del síndico como del guardián. La firma de dos de ellos debía acompañar las del guardián y síndico en el caso de las cuentas en dinero, y las del guardián en los autos del Libro de Cuentas pecuniarias.

\subsection{Libros de cuentas del Convento}

Una buena organización y control del Convento era fundamental para tener una economía saneada que permitiese su sustento. Su sistema contable se asentaba sobre un conjunto de libros y se implementaba un proceso de control de estos que permitía a los franciscanos afrontar, con cierta garantía, los retos de funcionamiento del Convento.

Se dispone del Libro de Cuentas dinerarias, Libro de Cuentas pecuniarias o en especie, Libro de Misas y Libro de Deudas.

\subsubsection{Libro de Cuentas dinerarias}

El libro de tenencia obligada más importante para analizar la economía del Convento era el Libro de Cuentas dinerarias (AHN, Clero, libro 23). Se divide en dos partes donde el síndico iba haciendo los apuntes de forma simultánea de acuerdo con el diario de las operaciones que se llevaban a cabo con el fin de captar los distintos hechos económicos que iban aconteciendo. En la primera parte se recogen las entradas o cobros, expresando la procedencia del dinero (normalmente en maravedíes, aunque también, excepcionalmente, se utilizaba el peso, debiendo el síndico realizar una operación de cambio) y el motivo de la entrada. En la segunda parte se registran los pagos o salidas y su destino. Estos libros debían estar firmados, además de por el síndico, por el guardián y dos consejeros auxiliadores.

Aunque no hubo modificaciones significativas del sistema de registro en todo el siglo, se puede observar algún intento de organizar el sistema de contabilidad existente en línea con la tendencia a la racionalización puesta en marcha por las autoridades ilustradas y que ya era efectiva en los años 70. Así, en los años 1770 y 1771 se hizo un intento de modificar el sistema de registro, aunque sin abandonar el sistema de cargo y data. En lugar de utilizar dos partes diferenciadas del libro, en la parte de las salidas empezaron a recogerse tanto salidas como entradas, de forma alternativa una y otra. La suma de las cantidades de cada apunte se iba haciendo en la misma hoja del Libro de Cuentas dinerarias escribiendo en los márgenes: izquierdo para las entradas, derecho para 
las salidas. Fue habitual que las cantidades apuntadas como salidas tuvieran reflejo de la misma cantidad en las entradas enfrentado así movimientos de las mismas cuantías en la misma hoja.

Con el fin de facilitar la rendición de cuentas, entre los apuntes contables realizados cronológicamente, se incorporaban cuentas que daban razón de la diferencia de ingresos y pagos ("resta"), denominadas Cuenta resumen, generándose alcance a favor del Convento, en caso de saldo positivo ("contra en síndico"), o a favor del síndico, en caso de saldo negativo, quedando el Convento provisionalmente como deudor ("contra el convento"). Estas Cuentas resumen se hacían en un momento arbitrario, cuando el comisario decidía hacer una visita al Convento.

La contabilidad existente en el Convento responde a la necesidad de tener información, adaptar a medio plazo los ingresos probables y poder satisfacer las necesidades de la comunidad para el mantenimiento propio de los frailes, buscando una autosuficiencia con una evolución paralela de ingresos y gastos.

Además de las anteriores Cuentas resumen, a partir de la segunda mitad de siglo, periodo que, como se analiza a continuación, coincidió con un incremento de la actividad comercial desarrollada en torno al Convento, se modificó también el sistema de rendición de cuentas, no así el de registro. Empiezan a elaborarse las llamadas Cuentas generales, así denominadas por el síndico encargado de su elaboración. En este caso, el estado informativo elaborado incluía resumen de las Cuentas resumen anteriores. Lo que se hacía en ellas era evaluar los ingresos y gastos realizados por el convento en un periodo determinado más amplio que la Cuenta resumen. De nuevo nos encontramos con modificaciones derivadas de la línea de racionalidad impuesta en distintos sectores de la economía y que ya hemos visto a la hora de apuntar los registros contables con objeto de conseguir una gestión más eficiente.

Por último, otra modificación del sistema contable fue el llamado Auto general. Es un estado de información donde se resumen las Cuentas generales desde el inicio hasta el final del mandato de un guardián. Del mismo modo, se escribe intercalado en la parte de gastos del Libro de Cuentas dinerarias. Esos Autos generales pueden considerarse como un estado intermedio de tesorería que informa de la tesorería recibida por un guardián así como de los déficits o superávits que se generaban a lo largo de su mandato. Estos informes presentaban por primera vez una visión retrospectiva de los movimientos de tesorería a lo largo de amplios periodos de tiempo en los que el Convento llevaba en funcionamiento. El objetivo de la introducción de estos autos era facilitar el control de las actuaciones del convento vinculado a la dirección de cada guardián. Con este proceder no solo se pretendía el control, sino cuantificar la responsabilidad en la gestión de los encargados del Convento, garantizando así una estricta función de inspección para evitar poner en peligro la supervivencia de la comunidad.

Esta evolución del sistema de rendición de cuentas, aunque fuese mínima, estaba encaminada a satisfacer las exigencias de la responsabilidad en la gestión. En un entorno de crecimiento de las operaciones económicas, se desarrolló este procedimiento como un factor clave para emitir un juicio sobre la gestión llevada a cabo por el guardián del Convento por parte del presidente de las diócesis sobre quien recaía la administración del Convento. El sistema contable en las entidades religiosas debía no solamente registrar los ingresos y pagos, sino facilitar los medios y medidas para demostrar y poder juzgar la gestión llevada a cabo, puesto que el control sobre el Convento se apoyaba en los registros contables con el fin de controlar las actividades y proporcionar análisis de desviaciones de ingresos y gastos (Araújo y Gomes, 2014; Maté et al., 2017).

Así, en la primera mitad de siglo observamos cómo los libros están firmados por el guardián, el síndico y dos hermanos. En los procesos de revisión de las cuentas, el comisario firmaba además en las Cuentas resumen. A partir de la creación de esa información intermedia de tesorería, Cuentas generales y Autos generales, se incrementa el proceso de control, de forma que las Cuentas generales debían añadir la firma del presidente de la congregación en los Autos generales.

\subsubsection{Otros libros de cuentas}

Además del libro de Cuentas dinerarias, la gestión del Convento se apoyaba en otra serie de libros esenciales para su funcionamiento: Libro de Cuentas pecuniarias o en especie, Libro de Misas y Libro de Deudas.

El Libro de Cuentas del trigo y azafrán y lana, llamado también Libro de Cuentas pecuniarias, reúne las cantidades por estos conceptos que entraron en el Convento (AHN, Clero, libro 21). Incluye las cuantías recaudadas por cada misa impartida en el Convento o en localidades cercanas a los Llanos. Se registraron asimismo bienes por pequeñas donaciones o limosnas. Estas aportaciones procedían de las localidades donde los presbíteros tenían influencia.

Las entradas debían ser pesadas y controladas por el guardián, quien debía anotarlas y firmarlas en primera instancia. Junto a él firmaban dos presbíteros de rango. Asimismo, este libro contiene las salidas de estas especies, unas veces con destino al molino para la comunidad, otras para pagos a particulares que habían trabajado para el Convento, es decir se incluyeron pagos de salarios en especie. En ocasiones, se utilizaron también como instrumento de cambio para la adquisición de otros bienes. Podía ocurrir que una parte de estos depósitos se destinaran a otros conventos de la misma comunidad. Otras veces no se especifica razón que justifique la salida de las mercancías.

El Libro de Misas registraba el número que podían celebrar los frailes previa autorización de la congregación. Era la llamada "licencia de misas". Supusieron una importante fuente de ingresos y por ello estaban sujetas a control por el definitorio de la Diócesis de Cartagena (AHN, Clero, libro 20). La limitación en la autorización de misas tenía por objeto no romper la "Regla de pobreza" defendida en la Constitución franciscana. La relación de las misas celebradas se hacía cada mes y se informa de cómo fueron pagadas: en dinero, o bien en grano, azafrán, lienzo, vino o cera. Se detallaba quien impartía cada misa y cuanto se cobraba por ellas. Dicha relación iba firmada por esos mismos sacerdotes. Las entradas debían estar registradas en los libros correspondientes: de cuentas dinerarias o pecuniarias.

En el Libro de Deudas, debían anotarse las deudas a favor y en contra del Convento (AHN, Clero, libro 24). Las deudas a favor del Convento se agrupaban por localidades, apuntándose los nombres de los deudores y las pequeñas aportaciones que se van restando de una cantidad mayor que el Convento entregó previamente. A continuación, se apuntaban sucesivas entregas y los años en que se iban haciendo tales devoluciones. Iban tachándose las deudas conforme se cubrían las cantidades totales prestadas. El libro está cumplimentado en fechas posteriores a las de nuestro período de estudio; sin embargo, recoge préstamos contraídos desde 1765. El Convento apenas tuvo deudas en contra. Solo se registra una en todo el período a favor de otro convento y a pagar en trigo y en varias misas a celebrar. 
El proceso de reconocimiento de deudas a favor del Convento se llevaba a cabo a partir del reconocimiento de distintos epígrafes para clasificar las entradas. El primer concepto, por ser más frecuente, era el de grano. Este se llevaba a la guardianía desde donde podía prestarse a particulares, destinarse al consumo de los miembros de la comunidad, o venderse o cambiar por otros productos. Dichas salidas debían ser autorizadas por el guardián en la forma acostumbrada. El segundo concepto era el de hábitos. Los solía dar el Convento a particulares para el enterramiento de sus difuntos. El pago solía hacerse de forma aplazada, sin que conste incremento de la cantidad endeudada por el atraso en el pago. El tercer concepto era el de misas. Los feligreses se endeudaban también para que los conventuales impartiesen misas para sus familiares. En cuarto lugar, se registraron deudas en lana. Por último, menores deudas a favor del convento se hicieron en arroz, aceite y harina. Entre todas las secciones, se insertaban hojas en blanco porque los apuntes se hacían de forma simultánea.

En función de los apuntes de este libro, el Convento debió actuar como prestamista a particulares. En el caso de préstamo de grano, sus funciones se aproximaban a las desarrolladas por los pósitos, aunque a diferencia de estos que eran municipales, de titularidad eclesiástica. Los pósitos dedicaron sus fondos bien a auxiliar a los campesinos en épocas de dificultad, prestándoles simientes en épocas de siembra, bien a prestar a consumidores para su acopio. Y del mismo modo actuó la comunidad conventual para auxiliar a los feligreses. Así se deduce de las entradas de este libro donde se exponen los compromisos adquiridos con particulares quienes pagaban favores que el Convento les hizo, como la atención a enfermos o la consideración a difuntos.

\section{Análisis de la estructura general de ingresos y gastos del Libro de Cuentas dinerarias}

El análisis realizado abarca prácticamente el siglo XVIII; son 71 años de apuntes diarios que hacen minucioso y lento el trabajo, pero del que resulta una serie amplia para observar cómo ha evolucionado económicamente la institución.

Este estudio de los flujos económico-financieros va más allá del objetivo de tomar y rendir cuentas, permitiendo la visibilidad de la actividad económica del Convento, así como su interpretación en un determinado contexto geográfico, sureste español, y temporal, siglo XVIII. La segregación de la comunidad que habitaba este convento se produjo en el año 1795 , pero no se conservan los libros que registran su actividad. Sus propiedades permanecieron hasta la desamortización de 1832, pero no existe documentación que atestigüe acerca de su gestión esos años.

\subsection{Análisis de la estructura del Libro de Cuentas dinerarias}

A partir del análisis de todos los legajos que componen el Libro de Cuentas dinerarias, se puede observar cómo la práctica contable realizada durante toda esta etapa se centraba únicamente en la derivada del método de cargo y data, guiado por un marcado criterio de caja. En ningún momento se utilizó el método de partida doble para llevar a cabo la contabilidad de esta institución, por lo que no se dispone de información sobre el patrimonio del Convento.

La contabilidad de las instituciones monásticas y conventuales estaba destinada a reflejar las relaciones de tipo bilateral entre el Convento y los agentes relacionados con él (Hernández, 2005, pág. 104), y asimismo ocurría en el Convento estudiado. Esta contabilidad de "pura tesorería" reflejaba únicamente la corriente monetaria de cobros y pagos, a pesar de que la terminología utilizada en el registro de las operaciones hiciera referencia a otros términos que fueron cambiando en el período analizado (Donoso, 2005).

En los registros de cuentas dinerarias se emplean indistintamente los vocablos "recibo", "entradas" o "cargo" para designar los cobros; "gasto", "salidas" o "data" para designar los pagos y "resta" o "alcance del Convento" para la diferencia. No hay razón que explique el cambio de términos, puesto que incluso a veces coincide el mismo tesorero como encargado de los apuntes de entradas y salidas donde se utiliza la distinta terminología. Cuando se utiliza el término "ingresos”, se refiere únicamente a las entradas en la tesorería del Convento. De igual forma, cuando se habla de gastos se hace referencia a los pagos o entregas de fondos y, por tanto, a las disminuciones de tesorería. Por ello, en el análisis de los conceptos definidos, si bien podría pensarse que se sustentan sobre el principio de devengo, han sido definidos atendiendo al principio de caja que caracteriza las cuentas Convento, no recogiendo la corriente real del mismo en su totalidad.

Se han agrupado tanto los ingresos como los gastos registrados en el Libro de Cuentas dinerarias en distintas categorías en función de su naturaleza. Con relación a los ingresos, de la categoría limosnas y misas se obtuvieron la mayor parte de las entradas, pero no siempre se cobraron en moneda, sino en grano, lienzo, nieve, azafrán, vino o cera. Hubo otras entradas debido a las ventas que hicieron de víveres y de textiles. En este último caso, solían venderse hábitos que habían sido usados por los frailes y que cedían para enterramientos para seglares. A estos ingresos se sumaban los derivados de donaciones y préstamos. Y por último, hay un ingreso que se refleja la importancia de la actividad comercial que es el correspondiente a la feria.

Con respecto a las salidas, los apuntes son más diversos que en el de entradas, estando dirigidos tanto al mantenimiento de los integrantes de la Comunidad, como al mantenimiento y construcción del recinto conventual y su iglesia. El Libro de Cuentas dinerarias recoge más de 50 conceptos, que en este trabajo se han agrupado de forma homogénea para una mayor comprensión y análisis de datos. Además, en el registro de salidas el contador solía agrupar en un mismo apuntes salidas destinadas a distintos pagos, de forma que ha habido que desagregarlos minuciosamente en cada registro para adaptarlos a la clasificación utilizada. Los conceptos de gastos que se han empleado son: salarios o pagos al personal (lavandera, costurero, tejedores, peleteros y zapateros, herreros, jornaleros o caldereros); pagos de comestibles; devolución de préstamos; actividades benéficas (gastos de mantenimiento del hospicio y de los padres superiores y de sus madres); materiales y enseres (obras y conservación del patrimonio ); ganado (compra y mantenimiento de ganado); secretaría (correos, libros, tinta y papel); viajes (gastos por desplazamiento y portes para adquirir o vender mercancías); ventas de textiles y otros gastos (fundamentalmente medicamentos, tabaco y bulas)

\subsection{Análisis de ingresos y gastos}

En las tablas 1 y 2, se muestra la evolución de los cobros y pagos totales. No se incluye en el análisis el alcance derivado de la diferencia entre cobros y pagos. Así se evidencia la evolución de estos evitando la distorsión que generan los arrastres del año anterior, así como las aportaciones del síndico para cubrir el déficit de algunos años. Los pagos, por tanto, solían ajustarse a las cantidades de liquidez disponibles, aun- 
que se buscaran mecanismos para incrementar los ingresos cuando las necesidades de gastos fuesen mayores. De este modo, se observa que la evolución del alcance es irregular tal y como se muestra en el gráfico 1 , aunque con una tendencia a mantenerse equilibrado en la mayoría de los años analizados

Gráfico 1

Evolución de ingresos, gastos y alcance (1718 -1789)

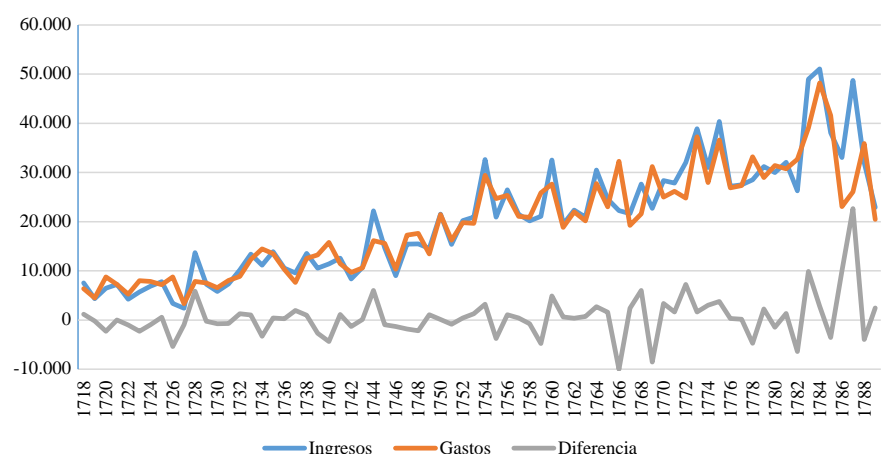

Fuente: Elaboración propia

En este trabajo, el análisis comparativo de ingresos y gastos se hace en términos relativos para evitar que una valoración desigual de la moneda desde principio a fin del siglo provocara inexactitudes en las conclusiones (véase tablas 3 y 4). Por tanto, los datos que se presentan están sin deflactar. Se advierte este análisis para explicar la validez de nuestros datos porque se han examinado las distintas partidas porcentualmente en relación con los datos totales, permitiendo su rápida comparación. El objetivo de este trabajo no exige dicha homogeneización.

\subsubsection{Evolución de los ingresos}

En el gráfico 2 se puede observar el peso relativo de los principales ingresos del Convento, diferenciando cómo evolucionan en la segunda mitad del siglo respecto a la primera, puesto que, como se puede ver en el gráfico 1, a partir de ese momento experimentan un crecimiento continuado

Gráfico 2

Evolución del peso relativo de los ingresos

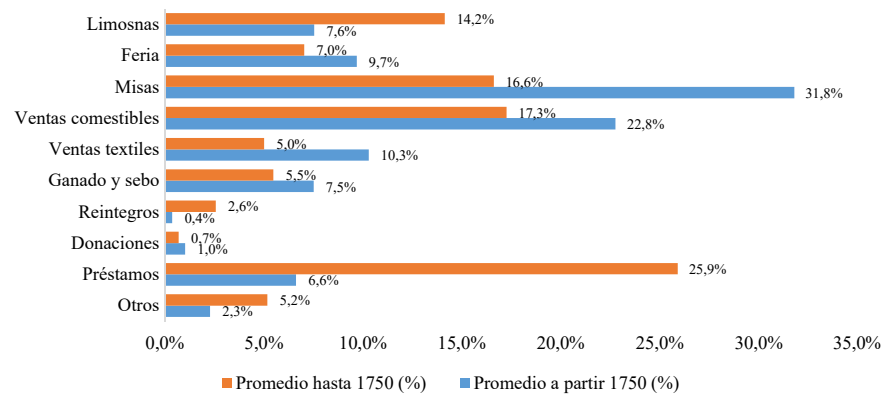

Fuente: Elaboración propia

Limosnas y misas supusieron el $40 \%$ de los ingresos totales al menos hasta la mitad de siglo, cumpliendo un papel fundamental para la subsistencia y funcionamiento del convento. Eran estos las actividades tradicionales de los frailes. Pero la base de crecimiento de los ingresos era débil. Impartir más misas competía a los superiores de la orden; obtener más limosnas dependía de las posibilidades de aportación de una población agraria. Es cierto que la renta de los trabajadores agrarios en este periodo era mayor que en años anteriores. La conocida expansión agraria del momento debió permitir a estos campesinos cierta liquidez compatible con dichos pequeños donativos (Anes, 1978). Lo que está claro es que, en estas décadas de principios del siglo XVIII, la actividad productiva del convento no era tan alta. En la segunda mitad del siglo, el protagonismo de ambas partidas se distanció. Las limosnas se redujeron como consecuencia de la menor disponibilidad de saldos de los trabajadores agrarios, con menores rentas agrarias y afectados por la subida de precios (Anes, 1970). Las misas, por el contrario, se incrementaron obteniendo un protagonismo esencial (del 17\% al 32\%). Se articuló ese incremento como un mecanismo de obtención de mayores recursos. Y este procedimiento sí dependía de quienes tenían que autorizar impartir un número mayor de misas, sus superiores. Advirtiendo que no se debía abandonar la regla de pobreza, aprobaron el sistema que les reportara más ingresos. Es probable que esta actuación fuera paralela a un mayor relajamiento de la rigidez acorde con las nuevas corrientes de pensamiento ilustrado.

Completaban el concepto de ingresos las ventas que los frailes solían hacer de víveres que ellos mismos producían o bien los derivados de entregas de particulares. Durante todo el siglo, las ventas pasaron de representar el 17\% de promedio de los ingresos en la primera mitad de siglo a un $23 \%$ en la segunda, llegando algunos años a superar el 50\%. Incentivar la comercialización como un flujo de recursos para el convento fue utilizado desde mediados de siglo, en línea con la tendencia general de dinamizar los intercambios interiores impulsada por los gobernantes ilustrados. Esta evolución de las ventas es más significativa aún si se consideran las ventas de ganado. Su importancia relativa media pasó de un $5 \%$ a un $8 \%$ en la segunda mitad de siglo equilibrando los déficits anuales y alcanzando el $25 \%$ de los ingresos totales algunos años. Su venta se incrementó especialmente desde 1763.

En este contexto de incremento de la actividad comercial, es de resaltar la feria celebrada junto al Convento como fuente de ingresos básica para el equilibrio financiero del convento, cuyo peso en los ingresos llegó a alcanzar el 10\% de valor medio, aunque algunos años llegó incluso a superar el $20 \%$. La feria fue autorizada en 1710 como un privilegio a la ciudad de Albacete dado por Felipe V por la lealtad a la corona en la Guerra de Sucesión (AGS, DGR, $2^{\mathrm{a}}$ R., 2952) (López, 2004). Fue especialmente innovadora para una institución conventual utilizar este recurso y resulta ser un aspecto diferenciador en relación con las actividades productivas utilizadas por otras entidades. Instituciones similares analizadas cuentan con la explotación de la tierra o con la cesión de préstamos, censos, cuyas rentas permitieron mantener la institución. No obstante, en el caso de Los llanos, fue el incentivo a la comercialización - una actividad tan poco coherente con el recogimiento y pobreza que exigía la práctica de la observancia religiosa- la que dio sentido y solidez a la institución. De nuevo podemos observar que la vía para la obtención de recursos fue el fomento de estas actividades, que se potenciaron especialmente a partir de la segunda mitad del siglo. Las entidades religiosas también experimentaron la influencia ilustrada haciéndose compatible con el mantenimiento de las reglas franciscanas, adaptándose de esta forma a los nuevos tiempos.

En el Convento de Los llanos, dada la imposibilidad de arrendar tierras o establecer un importante número de censos sobre ellas, al carecer de patrimonio propio para ello, el desarrollo de la feria logró articular la comercialización de bienes primarios de la comarca, como consta en los libros de cuentas. La centralización del comercio en el convento primero en su interior y después con la celebración en sus 
afueras- propició la afluencia y el incremento no solo de las ventas, sino de las pequeñas limosnas que habitualmente se entregaban en pequeñas cantidades, y que fueron más altas los días de celebración. Observamos el incremento de esta actividad como fuente de financiación de la entidad coincidiendo con las medidas de estimulación del comercio acordes con las normativas liberalizadoras que se dieron desde mediados de siglo por el estado, que reproducían la aplicación de las nuevas corrientes económicas europeas.

La afluencia de gentes y el movimiento dinerario derivado de la feria despertó el interés del ayuntamiento de Albacete por celebrarla en el centro de la villa (AHPAB, Municipios, caja 4546). La aparente contradicción entre incentivo al comercio y recogimiento fue su debilidad. Este hecho fue la premisa que mantuvo el ayuntamiento para arrebatar al convento el disfrute de esta regalía que llevaba consigo el disfrute de un privilegio: la exención de tributos en las ventas. Las razones económicas toman peso a la hora de establecer pleitos para conseguir su traslado. Desde el concejo se argumentó que no era conveniente su celebración junto al convento porque contravenía las reglas de pobreza de la orden. Con objeto de limitar esta crítica, los frailes optaron por su celebración construyendo lonjas para las ventas para su uso los días de feria fuera de los límites del convento (1747). Se organizaba de forma que se pudieran seguir obteniendo beneficios de ella sin alterar el recogimiento eclesiástico. Los enfrentamientos congregación y concejo se incrementaron hasta su resolución definitiva en 1783 en los tribunales. El Consejo de Castilla autorizó, ahora sí, su traslado a la villa. A partir de este año, los ingresos de feria se suprimieron. Se mantuvieron limosnas que se solían incrementar este mes, porque los comerciantes mantuvieron su tradición de dejarlas a su paso por la dehesa de los Llanos, en el Convento, en la temporada de la celebración de la feria en la villa en Albacete, pero su repercusión negativa en las cuentas del convento fue drástica.

Por tanto, la vinculación de la feria con el convento fue básica para su funcionamiento, tal y como atestiguan la constancia y repetición de valores en todo el siglo XVIII y que explica el citado interés de mantener su celebración junto al recinto del convento.

Como se ha anticipado previamente en el Libro de Cuentas dinerarias, ese incremento del comercio que se observa en la segunda mitad de siglo impulsó a su vez los cambios en el registro contable. Es cierto que no hubo una reforma de mayor calado, como lo habría sido la implantación de la partida doble, pero la modificación del sistema de rendición de cuentas y el establecimiento de la Cuenta general y del Auto general mostraron un reforzamiento de los sistemas de control, en definitiva, la adaptación a la nueva realidad económica. Sin duda, no estuvieron ajenos a las corrientes de liberalización del comercio interior que los ilustrados defendieron con vehemencia en la segunda mitad del siglo XVIII. Ese espíritu de mayor apego a la ciencia, pese a tratarse de una institución basada en la fe, se muestra en la búsqueda de métodos más eficientes de gestión y, por tanto, más racionales.

Para cerrar el análisis se debe hacer referencia a los préstamos de particulares al convento. En la primera mitad de siglo tuvieron un peso medio de los ingresos del $26 \%$, llegando incluso al $44 \%$ en momentos puntuales. En la segunda mitad descendió su importancia al 6,6\% .Todos esos pagos al convento por particulares se hicieron en la primera mitad del siglo. Ello explica que su situación financiera fuera más débil entonces, con déficits continuos. Se hicieron necesarias esas aportaciones para el mantenimiento del convento. Esa necesidad, junto a la difusión del nuevo pensamiento económico basado en la apertura de los flujos comerciales y a las normativas que esperaban la intensidad de los intercambios, impulsaron la disposición a actuaciones relacionadas con el comercio. De hecho, esas aportaciones fueron innecesarias en la segunda mitad del siglo como muestra de que otras actividades más productivas se habían implantado.

Por último, otra fuente de ingresos, incluida en Otros Ingresos, fueron los salarios pagados al Convento por el trabajo en la iglesia de Chinchilla y que repercutieron en la institución. En la búsqueda de alternativas al aumento de ingresos, se presenta esta innovadora actuación. No se precisa cómo se incorporó este recurso. Tampoco existen otras instituciones similares donde se haga uso del servicio de los frailes como ayudantes en la construcción de edificios: capillas religiosas de otras localidades. Los salarios pagados a estos monjes fueron ingresos del convento. Estas cantidades se presentaron entre los años 1750 y 1760 . Están registrados en las entradas del convento como una actividad más. Esa partida representó el $13 \%$ de los ingresos totales en toda la década, llegando incluso al $38 \%$ en el año que se iniciaron las obras. Esta partida fue decisiva para lograr equilibrio presupuestario.

Por tanto, las misas y limosnas permitieron el funcionamiento del convento en la primera mitad del siglo. Los préstamos al convento completaron en ese período unos ingresos necesarios para el mantenimiento de la institución. Avanzado el siglo, las limosnas disminuyeron y hubo que arbitrar nuevas formas de obtener ingresos. Se incrementó el número de misas celebradas, que generaban importantes recursos para el convento, pero sobre todo se incentivaron actividades alternativas ingeniadas por los frailes para lograr el equilibrio de sus cuentas y que no estuvieron aisladas de la mayor apertura que dictaban las nuevas corrientes de pensamiento partidarias de mayor liberalización. Así, el aumento de la comercialización en la feria, el incentivo al comercio y la realización de trabajos de construcción fuera del convento proporcionaron una entrada de efectivo básica para obtener un equilibrio presupuestario.

\subsubsection{Evolución de los gastos}

Como puede observarse en el gráfico 3, hay un concepto que explica la mayor parte de los pagos del Convento: la compra de comestibles, que constituyó más del $50 \%$ de los pagos totales por el mantenimiento de la comunidad.

\section{Gráfico 3}

Evolución del peso relativo de los gastos

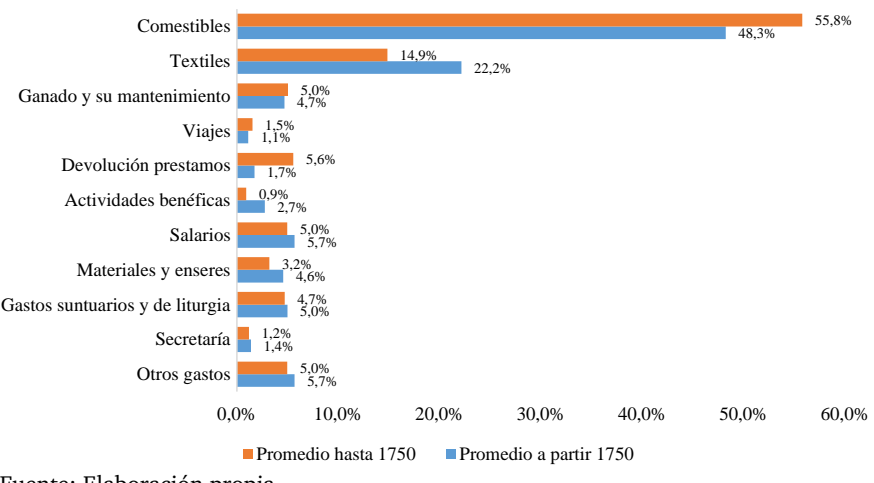

Fuente: Elaboración propia

Fue habitual que los gastos agrupados en este concepto supusieran la mayor parte del presupuesto conventual. En la primera mitad del siglo dos años fueron excepcionales. En 1722 , los registros en esta partida de gastos cayeron bruscamente hasta el $18 \%$, sin que conste mayor o menor número de residentes en el convento Lo único que puede justificar ese 
descenso es una contracción voluntaria de los gastos ante el déficit que se había producido en años anteriores (déficit acumulado del $13 \%$ ) y que no se llegó a corregir este año (24\%) ni el siguiente (40\%). La misma situación se repitió en 1727 , con reducción en términos absolutos en este concepto, pero también en los gastos globales (62\%). En este año, el descenso drástico de los gastos se explica por el déficit del año anterior: $160 \%$. Los años siguientes los gastos se limitaron casi a la adquisición de estos bienes (en torno al 70\% de los gastos totales), sin acometer reformas ni proyectos que ocupasen fondos del convento.

En términos absolutos, las cantidades fueron incrementándose en esta partida de adquisición de alimentos conforme avanzó el siglo, porque lo hicieron de forma progresiva en consonancia con el aumento del resto de gastos y, asimismo, de sus ingresos. Es posible que un mayor número de personas alojadas en el convento repercutiese en el aumento del consumo de productos básicos, como también de ropas y otros enseres. Este hecho se produjo durante la segunda mitad del siglo XVIII.

Una subida de precios, ligada a la conocida línea ascendente de estos de forma general en Castilla, podría justificar tal incremento. A partir del análisis de los registros contables para los años 1760-1770 (véase tabla 5), se observa que la mayor parte de los precios de los bienes que adquiría el convento con asiduidad se mantuvieron estables. Así ocurrió en la adquisición de legumbres, sal, avena, cebada. Sin embargo, dos productos adquiridos fuera de la provincia, el aceite y el arroz, experimentaron un aumento de precios. La compra de aceite supuso un incremento del gasto puesto que fue adquirido a un precio más del $100 \%$ mayor que a comienzos de esa década. El precio del arroz creció en torno al $45 \%$ para el mismo período. Ambos supusieron mayores salidas de dinero. Junto a ellos, también creció el precio del vino (un $196 \%$ más entre 1765 y 1766), pero pudo ser debido a una variación de la calidad de este.

El segundo concepto de gastos en importancia relativa fue las compras de textiles, normalmente hábitos y sandalias para los frailes, además de un pequeño porcentaje destinado a la adquisición de materia prima (lanas, lino, jabones) y de ajuar para el convento. Estos pasaron de representar un $15 \%$ de los gastos en la primera mitad de siglo a un $22 \%$ en la segunda.

Fue a partir de mediados del siglo XVIII, concretamente desde 1755, cuando los gastos en adquisición de textiles se incrementaron. Su peso se duplica ahora con respecto a la primera mitad del siglo y eso ocurre de forma independiente a la evolución de los gastos, es decir en años en que se redujo el gasto general, no disminuyó la adquisición de las telas. Probablemente se adquirían telas bastas con las que se elaboraban los hábitos, algunos para consumo de los mismos frailes, otros para su venta. De hecho, en las partidas de ingresos hubo constantes entradas por ventas de hábitos, como también se registran su venta a crédito en el Libro de Deudas. En cualquier caso, los textiles tuvieron un incremento del gasto relativo de importancia: un 190\% más entre los años 1755 y 1759, por ejemplo. Es cierto que hubo algunos años con cierto descenso en esta partida (1760-1771), pero también lo es que el incremento volvió a ser significativo en las últimas décadas analizadas.

Otra partida fundamental es la de los pagos relacionados con la adquisición de ganados e inversiones relacionadas con ellos. Estos gastos supusieron el $5 \%$ de los gastos totales del convento, lo que indica la existencia de una actividad productiva propia de esta institución. Hay que tener en cuenta que la compraventa de ganados solía suponer un negocio en sí mismo, que generaba importantes recursos para el convento, puesto que los saldos son positivos en esta confrontación de venta y compra de los mismos, con abultada cuantía en beneficio del convento. A partir de 1773 todos los años hubo ganancias con respecto a su venta, que también se hacía desde el convento. Los años de máxima ganancia relacionada con la compraventa de animales fueron 1773, 1775,1779, 1783 y 1789. Esos años las cuentas del convento registraron situaciones de equilibrio o incluso superávit que osciló entre el 10 y $20 \%$. Hubo, pues, una relación directa entre los ingresos relacionados con el ganado y ese equilibrio de las cuentas.

Entre las partidas de gastos, el capítulo de viajes fue constante, aunque no tuviera demasiado protagonismo (algo más del $1 \%$ del total). El problema es que no siempre se contabilizaron de forma desagregada los pagos por el porte de distintas mercancías, como se ha explicado en el epígrafe 3.1; en particular se incluyeron en aceite, arroz y pescado, cuando estos eran traídos desde Jaén y Alicante respectivamente. Los viajes pudieron incluir la cantidad de dinero que se les dio a quienes viajaron, la reparación de las carretas, la preparación del ganado, el alquiler de las caballerías cuando fue necesario e incluso las limosnas que daban los frailes durante el viaje.

Por último, la partida de devolución de préstamos supuso el $6 \%$ gastos asumidos por el convento durante la primera mitad del siglo XVIII, reduciéndose a un 1,7\% en la segunda mitad. No obstante, dichas devoluciones se produjeron tan solo en unos años. Así, por ejemplo, en nuestro primer año de análisis -1718- la devolución de estas cantidades llegaron a suponer el $25 \%$ de las salidas del convento. De nuevo, se repitieron varias veces en la década de los 20 (1720, 1723, 1724) donde se alcanza un porcentaje del $17 \%$ de los gastos anuales, cuando se produjo una salida de la mitad del dinero prestado. Entre 1748 y 1754 se volvieron a presentar en los gastos cantidades declaradas como devolución de cantidades previamente prestadas, aunque no se detalla el principal ni que hubiera intereses en su devolución. Aproximadamente recayeron en los gastos anuales con una presencia del $12 \%$. En algún caso, el préstamo lo hizo el mismo síndico y consta en los apuntes como devolución de préstamo, aunque este sistema formaba parte de la tarea del síndico: las aportaciones en caso de cuentas deficitarias para el convento. Así ocurrió por ejemplo en el año 1752.

Las dificultades económicas que se produjeron en la segunda mitad del siglo se reflejan en las salidas por donaciones, calificadas como actividades benéficas, puesto que solían ir destinadas a equilibrar las cuentas de otros conventos, normalmente de monjas. Un $2,7 \%$ de los gastos de este convento se dirigían a estas otras instituciones. Al parecer, una mayor estabilidad financiera de este convento posibilitaba que acudiera en auxilio de otros. Se produjeron fundamentalmente entre los años 1783 y 1785; fue un gasto asumible por el convento en un momento en que los saldos eran positivos.

Además de estas partidas de carácter recurrente, hubo otras salidas de carácter extraordinario. La reclamación de la feria por parte del convento ante los tribunales con el litigio con el ayuntamiento de Albacete supuso una importante salida de dinerario. Hubo que pagar las gestiones realizadas por el abogado, quien representó los intereses del convento en Madrid. Así, en el año 1780 se incorporó este gasto a las partidas habituales. Los gastos del viaje, así como los honorarios del abogado, notario y acompañantes, justifican salidas en las cuentas del convento.

Y junto a esta partida extraordinaria destaca otra, hecha de forma puntual, pero que anualmente pudieron ser una salida significativa en el año 1744: la compra de bulas eclesiásticas. 
Los otros dos años en que se registraron su cuantía fue mínima. Más habitual, relacionadas con la liturgia, fue lo gastado de forma constante en cera, junto a libros relacionados con la doctrina eclesiástica ( $5 \%$ de los gastos anuales).

Resumiendo, los gastos de la entidad estuvieron basados en la adquisición de víveres. No obstante, desde mediados del siglo XVIII, el incremento de los gastos estuvo asociado a actividades relacionadas con las nuevas actuaciones emprendidas por los frailes. Gastos derivados de la adquisición de textiles, de ganados con que obtener beneficios, en definitiva actividades relacionadas con el proceso de inversión y de las cuales se derivaron alcances positivos. Gastos extraordinarios como los necesarios para la remodelación del edificio completan el destino de los principales ingresos de la institución.

\section{Discusión y conclusiones}

Este trabajo permite percibir las influencias de las corrientes sociales y económicas que desde la segunda mitad del siglo XVIII se difundían por Castilla, de la mano de las corrientes ideológicas ilustradas, a través del análisis de la contabilidad del Convento de los Llanos. Los principios de la Ilustración estaban difundiéndose en España y debieron tener repercusión en el modo en que se gestionaban instituciones, también religiosas, pese a que estas estuviesen guiadas por principios relacionados con el recogimiento y la pobreza. La adaptación a las nuevas circunstancias económicas se evidencia en la evolución de la institución estudiada.

Este trabajo contribuye mostrando las modificaciones del sistema contable, basado en cargo y data, de acuerdo con las transformaciones de las actividades en el convento derivadas tanto de su adaptación a una nueva realidad económica como a la difusión de las corrientes de racionalización en la gestión que conocían de la ideología dominante en la segunda mitad del siglo XVIII. Manteniendo la esencia del sistema contable, se introdujeron mejoras en los registros, como fueron la elaboración de las Cuentas generales y los Autos generales, que eran como estados de tesorería intermedios, que básicamente pretendían mejorar la rendición de cuentas hacia terceros con ese objetivo de controlar la institución, de favorecer y de hacer más eficiente y responsable la gestión. Este proceso fue coetáneo al crecimiento de las operaciones económicas y permitía al guardián del convento -máximo responsable de las labores de control- emitir un juicio sobre la gestión, de la que luego debía rendir cuentas ante los responsables del control externo: comisario y presidente, titulares de la diócesis y de la orden respectivamente. Control interno y externo se compatibilizaban de este modo.

El estudio de las cuentas del convento permite apreciar la evolución de sus ingresos y gastos, de los que se observa una evolución diferenciada en la primera y segunda mitad del siglo. Los alcances negativos fueron poco frecuentes ya que se asumían los gastos que se podían afrontar con los ingresos habituales. En los casos que existían déficits, fueron cubiertos con aportaciones hechas por el síndico. Este proceso fue habitual en la primera mitad del siglo. Hacia 1755, y sobre todo ya en los años 60, la orientación de la actividad económica del convento cambia de forma que se incrementaron los flujos de dinerario haciendo por ejemplo innecesario el endeudamiento del convento mediante la solicitud de préstamos a particulares. El incentivo a la comercialización como el mayor flujo de recursos al convento estaba en línea con la defensa de las actividades artesanales y comerciales defendidas por los ilustrados en este mismo período, algunos de los cuales ocupaban cargos señalados desde donde impulsaban medidas legislativas acordes con una mayor liberalización y facilidad de comercio interior.

Los resultados del estudio evidencian lo innovador para una institución conventual de la utilización de la feria como una de sus principales actividades productivas, dando solidez financiera al convento. La ausencia de "recogimiento y pobreza" fue reiteradamente utilizada por los concejales de la villa para arrebatar esta feria a la orden franciscana, como finalmente ocurrió en 1783. Los dirigentes de la diócesis reclamaban seguir las reglas de la orden, pero defendiendo a la vez la concurrencia y el desarrollo de una actividad que generaba recursos y que, en definitiva, sustentaba a la comunidad. Estos dirigentes, procedentes de Valencia y de Cartagena, no debían estar al margen de las nuevas corrientes ilustradas.

En definitiva, este convento muestra, con su actividad contable, la evolución económica de la institución y de la realidad económica. Las variaciones de las actuaciones económicas de los frailes fueron perceptibles en la segunda mitad del siglo fundamentalmente. Las dificultades de su crecimiento en la primera mitad del siglo hicieron a sus dirigentes la necesidad de reinventarse y así lo hicieron en la segunda mitad. Se incorporaron actividades que generaron un importante flujo de dinerario: la feria, las ventas fuera de ella y el trabajo de los frailes fuera del convento. Todo ello necesitó de transformaciones del sistema contable con la articulación de más sistemas de control, incluyéndose estados intermedios de tesorería. No se modificó el sistema de registro, pero sí lo hizo el sistema de control. Y todo ello se hizo a la luz del movimiento ilustrado, cuando este pensamiento se difundía por las instituciones dando una mayor racionalidad a los sistemas de gestión.

\section{Financiación}

Esta investigación no recibió ninguna subvención específica de organismos de financiación de los sectores público, comercial o sin ánimo de lucro.

\section{Conflicto de intereses}

Los autores declaran que no tienen ningún conflicto de intereses.

\section{Fuentes y referencias}

\section{Fuentes manuscritas}

Archivo Histórico Nacional. Sección Clero Secular-Regular. Libros 37, 38, 39 y 40; carpeta 799, 12, y caja 4613.

Archivo Histórico Provincial de Albacete (AHPAB), Sección Municipios, Caja 4546.

Archivo General de Simancas. Dirección General de Rentas, $2^{\mathrm{a}}$ Remesa, legajo 2.952.

\section{Fuentes impresas}

Anes, G. (1970). Las crisis agrarias en la Edad Moderna. Madrid: Taurus.

Anes, G. (1978). Tendencias en la producción agraria en tierras de la Corona de Castilla (Siglos XVI a XIX). Hacienda Pública Española, 55, 97-111.

Araujo, D., \& Gomes, D. (2014). Accounting for religion or accounting for women: The case of the monaster of Santa 
Ana of Viana do Castelo (1701-1895). Lisboa: $7^{\circ}$ Encontro de História da Contabilidade de OTOC.

Calvo Cruz, M. (1999). La contabilidad de los espolios y vacantes. El caso de la Diócesis de Canarias 1753-1851. Las Palmas de Gran Canaria: Universidad de Las Palmas.

Carrión Íñiguez, V. (2006). Los Conventos franciscanos en la provincia de Albacete. Historia y Arte. Murcia: Instituto Teológico de Murcia.

Carrión Íñiguez, V. (2010). El convento de franciscanos descalzos en la ermita de los Llanos. En M. R. Pardo Pardo, \& L. G. García Sauco Beléndez, La feria de Albacete en el tiempo. Aspectos sociales, culturales y económicos (págs. 140-153). Burgos: Pubalsa.

Donoso Anes, R. (2005). Estado actual de la investigación en historia de la contabilidad. Revista de ContabilidadSpanish Accounting Review, 8(15), 19-44. https: / / revistas. um.es/rcsar/article/view/388561

Ghinato, A. (1975). Para una lectura actual de la Regla. Selecciones de Franciscanismo, 4(10), 66-94.

Hernández Borreguero, J. (2002). El Cabildo Catedral de Sevilla: organización y sistema contable (1625-1650). Sevilla: Universidad de Sevilla.

Hernández Borreguero, J. (2008). El Hospital de Santa Marta de Sevilla: gestión económica y contable (siglos XV a XVIII). Actas del XIII Congreso ASEPUC.

Hernández Esteve, E. (2005). Reflexiones sobre la naturaleza y los orígenes de la contabilidad por partida doble. Pecunia, 1, 93-124.

Jiménez Montañés, A., \& Villaluenga de Gracia, S. (2000). Instituciones de acogida en Toledo en el siglo XVI: el Hospital de la Santa Cruz. Aspectos contables. En U. d. Mancha, Ed., Ensayos sobre normalización, globalización e historia de la contabilidad, 343-370.

Lillo, J. L., \& Álvarez, J. M. (2006). Contabilidad y cobros de rentas en la Santa Capilla de San Andrés de Jaén. Dos siglos y medio tras la búsqueda de la eficiencia (16501900). De Computis. Revista Española de Historia de la Contabilidad, (3)4, 68-118. http://dx.doi.org/10.26784/ issn.1886-1881.v3i4.204

Llopis, E. (1995). Una gran "empresa" agraria y de servicios espirituales: el Monasterio Jerónimo de Guadalupe, 1389-1835. Documentos de Trabajo de la Facultad de Ciencias Económicas y Empresariales, 18. Madrid: Universidad Complutense.

López Pérez, M. (2004). Ferias y mercados en Castilla al final del Antiguo Régimen (Tesis doctoral). Madrid: Universidad Complutense.

López Pérez, M., \& Pérez Morote, R. (2007). El sistema de información contable del Hospital de San Julián de Albacete entre 1838 y 1859. De Computis. Revista Española de Historia de la Contabilidad, 4(6), 55-117. http: //dx.doi.org/10.26784/issn.1886-1881.v4i6.281

Maté Sadornil, L., Prieto Moreno, M., \& Santidrián Arroyo, A. (2017). El papel de la contabilidad monástica a lo largo de la historia en el orbe cristiano. Una revisión. Revista de Contabilidad - Spanish Accounting Review, 20, 143-156. http://dx.doi.org/10.1016/j.rcsar.2016.10.003

Maté, L., Prieto, B., \& Túa, J. (2004). La actividad financiera del Monasterio de Silos en el siglo XVIII a través de sus libros de cuentas. De Computis. Revista Española de Historia de la Contabilidad, 1(1), 97-124. http://dx.doi.org/ 10.26784/issn.1886-1881.v1i1.242

Napier, C. (2006). Accounts of change: 30 years of historical accounting research. Accounting, Organizations and Society, 31(4-5), 445-507. https://doi.org/10.1016/j.aos.
2005.12 .004

Pezzi, E. (1994). Libro de Cuentas del Convento franciscano de Cuevas de Almanzora, 1670-1693. Almería: Unicaja.

Rivero, D., Gallego, E., \& Ramos, A. (2005). La rendición de cuentas en la Orden del Cister de Castilla: el Libro de Estados del Monasterio de Oseira (1614-1832). De Computis. Revista Española de Historia de la Contabilidad, 2(2), 181-198. http://dx.doi.org/10.26784/issn. 1886-1881.v2i2.232

Salvador Montiel, M. D., \& Ruiz Lamas, F. (2011). El régimen administrativo y contable del Hospital de Caridad de la Coruña en el siglo XVIII. De Computis. Revista Española de Historia de la Contabilidad, 8(14), 156-179. http://dx. doi.org/10.26784/issn.1886-1881.v8i14.111

Villaluenga de Gracia, S. (2004). La aparición de la partida doble en la Iglesia: el diario y los mayores de la Catedral de Toledo, 1533-1539. De Computis. Revista Española de Historia de la Contabilidad, 2(3), 147-170. http://dx.doi. org/10.26784/issn.1886-1881.v2i3.218

\section{Anexos}


Tabla 1. Ingresos registrados en el Libro de cuentas 1718-1789. Valores absolutos

\begin{tabular}{|c|c|c|c|c|c|c|c|c|c|c|c|}
\hline & Limosnas & Feria & Misas & $\begin{array}{c}\text { Ventas } \\
\text { comestibles }\end{array}$ & Ventas textiles & $\begin{array}{c}\text { Ganado } \\
\text { y sebo }\end{array}$ & Reintegros & Donaciones & Préstamos & Otros & Total \\
\hline 1718 & 2.843 & 780 & 736 & 1.821 & 410 & 601 & 0 & 0 & & 376 & 7.565 \\
\hline 1719 & 1.396 & 377 & 324 & 1.181 & 348 & 717 & 0 & 0 & & 0 & 4.343 \\
\hline 1720 & 2.429 & 826 & 279 & 1.986 & 337 & 480 & 87 & 0 & & 45 & 6.469 \\
\hline 1721 & 1.333 & 225 & 1.142 & 2.879 & 154 & 810 & 99 & 0 & & 607 & 7.249 \\
\hline 1722 & 1.083 & 1.028 & 785 & 1.070 & 0 & 100 & 118 & 0 & & 54 & 4.237 \\
\hline 1723 & 2.266 & 608 & 1.824 & 0 & 44 & 130 & 260 & 0 & & 578 & 5.710 \\
\hline 1724 & 2.886 & 608 & 1.585 & 795 & 58 & 338 & 0 & 0 & & 625 & 6.894 \\
\hline 1725 & 2.492 & 1.036 & 1.460 & 2.025 & 122 & 0 & 515 & 0 & & 148 & 7.797 \\
\hline 1726 & 1.889 & 601 & 504 & 0 & 60 & 312 & 0 & 0 & & 0 & 3.366 \\
\hline 1727 & 539 & 700 & 462 & 111 & 160 & 0 & 0 & 0 & & 444 & 2.416 \\
\hline 1728 & 1.859 & 1.105 & 4.030 & 5.093 & 1.483 & 56 & 92 & & & & 13.718 \\
\hline 1729 & 2.391 & 762 & 1.734 & 754 & 790 & & 713 & & & 150 & 7.294 \\
\hline 1730 & 2.196 & 559 & 480 & 1.512 & 740 & 225 & 90 & & & & 5.802 \\
\hline 1731 & 2.215 & 501 & 1.983 & 731 & 1.006 & 577 & 335 & & & & 7.348 \\
\hline 1732 & 4.330 & 781 & 1.172 & 1.110 & 1.556 & 1.218 & & & & & 10.167 \\
\hline 1733 & 2.445 & 300 & 2.796 & 4.595 & 1.034 & 2.207 & & & & & 13.377 \\
\hline 1734 & 3.028 & & 3.152 & 1.000 & 836 & 23 & 143 & & 3.000 & & 11.182 \\
\hline 1735 & 4.124 & 500 & 3.572 & 2.099 & 676 & 170 & & & 2.745 & & 13.886 \\
\hline 1736 & 2.216 & 716 & 2.533 & 4.068 & 493 & 500 & & & & & 10.526 \\
\hline 1737 & 1.625 & 453 & 1.391 & 3.916 & 132 & 180 & 1.875 & 0 & & 0 & 9.572 \\
\hline 1738 & 2.943 & 525 & 4.099 & 2.906 & 116 & 1.563 & 0 & 0 & & 1.375 & 13.527 \\
\hline 1739 & 3.271 & 875 & 1.865 & 2.970 & 417 & 532 & & & & 600 & 10.530 \\
\hline 1740 & 1.675 & 845 & 871 & 2.506 & 1.772 & 1.581 & 2.153 & 0 & & 0 & 11.403 \\
\hline 1741 & 616 & 684 & 2.228 & 4.791 & 1.045 & 2.390 & & 59 & & 749 & 12.562 \\
\hline 1742 & 2.816 & 887 & 1.533 & 1.661 & 535 & 221 & 438 & & & 274 & 8.365 \\
\hline 1743 & 719 & 1.606 & 3.083 & 4.408 & 651 & 257 & & & & & 10.724 \\
\hline 1744 & 462 & 1.772 & 12.428 & 2.915 & 1.936 & 270 & 900 & & 1.500 & & 22.183 \\
\hline 1745 & 1.039 & 1.997 & 3.548 & 5.527 & 784 & 1.676 & 40 & & & 33 & 14.644 \\
\hline 1746 & 495 & 3.792 & 1.620 & 724 & 135 & 1.731 & & 309 & & 220 & 9.026 \\
\hline 1747 & 852 & 376 & 4.051 & 3.652 & 1.487 & 3.150 & & & & 1.857 & 15.425 \\
\hline 1748 & 1.429 & 967 & 2.461 & 2.463 & 878 & 497 & 5 & & 6.725 & 36 & 15.461 \\
\hline 1749 & 685 & 2.141 & 2.743 & 5.049 & 1.301 & 1.222 & 240 & 1.150 & & 42 & 14.573 \\
\hline 1750 & 1.428 & 1.960 & 2.798 & 1.865 & 1.214 & 344 & & & 3.801 & 8.137 & 21.547 \\
\hline 1751 & 389 & 1.832 & 4.754 & 5.979 & 1.532 & 237 & & 270 & & 380 & 15.373 \\
\hline 1752 & 944 & 2.446 & 7.561 & 5.216 & 624 & 225 & 9 & & & 3.200 & 20.225 \\
\hline 1753 & 1.167 & 3.044 & 5.442 & 6.125 & 886 & 2.225 & 34 & & & 2.000 & 20.923 \\
\hline 1754 & 582 & 4.549 & 6.655 & 13.485 & 1.254 & 2.009 & & 145 & & 3.942 & 32.621 \\
\hline 1755 & 1.197 & 3.210 & 6.602 & 3.792 & 3.433 & 863 & & 20 & & 1.795 & 20.912 \\
\hline 1756 & 3.922 & 3.244 & 7.884 & 3.828 & 1.913 & 3.062 & & 134 & & 2.461 & 26.448 \\
\hline 1757 & 3.826 & 2.888 & 6.183 & 2.141 & 944 & 1.006 & 60 & 290 & 2.650 & 1.500 & 21.488 \\
\hline 1758 & 680 & 2.611 & 5.956 & 2.274 & 3.098 & 1.781 & & 150 & 1.500 & 2.100 & 20.150 \\
\hline 1759 & 1.269 & 2.495 & 7.003 & 2.714 & 3.734 & 279 & 20 & 600 & & 2.989 & 21.103 \\
\hline 1760 & 2.207 & 3.968 & 8.148 & 7.390 & 3.558 & 113 & & 4.071 & & 3.075 & 32.530 \\
\hline 1761 & 859 & 3.830 & 9.195 & 2.794 & 1.400 & 702 & & 160 & & 500 & 19.440 \\
\hline 1762 & 3.293 & 4.318 & 5.462 & 3.556 & 2.253 & 1.971 & 600 & 900 & & & 22.353 \\
\hline 1763 & 3.121 & 1.393 & 6.051 & 5.807 & 1.348 & 2.648 & 0 & 107 & & 451 & 20.926 \\
\hline 1764 & 6.639 & 2.209 & 8.434 & 10.591 & 1.356 & 1.255 & 0 & 0 & & 0 & 30.484 \\
\hline 1765 & 2.577 & 2.444 & 5.285 & 4.448 & 3.458 & 2.400 & 0 & 4.000 & & 0 & 24.612 \\
\hline 1766 & 4.538 & 4.460 & 3.852 & 7.763 & 841 & 540 & 0 & 244 & & 0 & 22.237 \\
\hline 1767 & 2.654 & 3.571 & 8.349 & 2.720 & 2.089 & 2.280 & 0 & 0 & & 0 & 21.663 \\
\hline 1768 & 2.556 & 2.091 & 12.153 & 4.621 & 4.790 & 1.118 & 0 & 0 & & 300 & 27.630 \\
\hline 1769 & 1.993 & 3.464 & 6.626 & 5.844 & 2.249 & 2.275 & 0 & 0 & & 260 & 22.711 \\
\hline 1770 & 467 & 3.332 & 8.412 & 10.954 & 2.773 & 1.348 & 0 & 0 & & 1.050 & 28.337 \\
\hline 1771 & 472 & 2.980 & 13.159 & 5.857 & 2.829 & 1.910 & 85 & 0 & & 550 & 27.842 \\
\hline 1772 & 1.844 & 3.378 & 14.520 & 9.369 & 2.079 & 804 & 0 & 0 & & 0 & 31.994 \\
\hline 1773 & 2.070 & 3.142 & 9.989 & 8.788 & 3.804 & 11.088 & 0 & 0 & & 0 & 38.880 \\
\hline 1774 & 1.003 & 2.919 & 11.618 & 9.303 & 4.970 & 1.184 & 0 & 0 & & 0 & 30.997 \\
\hline 1775 & 2.183 & 3.160 & 21.212 & 4.718 & 2.798 & 6.170 & 125 & 0 & & 0 & 40.365 \\
\hline 1776 & 1.878 & 4.011 & 12.540 & 4.025 & 4.595 & 157 & 0 & 0 & & 0 & 27.206 \\
\hline 1777 & 5.504 & 3.967 & 8.416 & 8.082 & 1.535 & 0 & 0 & 0 & & 0 & 27.504 \\
\hline 1778 & 3.713 & 1.785 & 10.069 & 7.289 & 3.628 & 1.500 & 526 & 0 & & 0 & 28.511 \\
\hline 1779 & 1.464 & 2.585 & 11.905 & 6.422 & 1.799 & 7.039 & 0 & 0 & & 0 & 31.213 \\
\hline 1780 & 1.758 & 2.705 & 12.090 & 3.949 & 6.958 & 2.434 & 0 & 75 & & 0 & 29.970 \\
\hline 1781 & 1.068 & 2.532 & 15.038 & 5.016 & 5.617 & 2.291 & 200 & 300 & & 0 & 32.062 \\
\hline 1782 & 3.773 & 2.529 & 9.260 & 4.944 & 2.752 & 2.295 & 700 & 0 & & 15 & 26.269 \\
\hline 1783 & 4.482 & & 14.084 & 13.464 & 9.957 & 6.954 & 0 & 0 & & 0 & 48.941 \\
\hline 1784 & 2.735 & & 18.170 & 19.681 & 4.423 & 5.699 & 0 & 0 & & 336 & 51.043 \\
\hline 1785 & 4.403 & & 11.120 & 12.876 & 5.210 & 4.472 & 0 & 0 & & 0 & 38.081 \\
\hline 1786 & 3.093 & & 8.694 & 16.892 & 2.436 & 1.131 & 400 & 400 & & 0 & 33.048 \\
\hline 1787 & 2.022 & & 24.856 & 13.808 & 6.981 & 504 & 380 & 0 & & 156 & 48.706 \\
\hline 1788 & 2.707 & & 14.640 & 7.277 & 5.347 & 1.950 & 0 & 0 & & 23 & 31.943 \\
\hline 1789 & 1.079 & & 6.800 & 4.127 & 4.515 & 5.885 & 495 & 0 & & 0 & 22.901 \\
\hline
\end{tabular}


Tabla 2. Gastos registrados en el Libro de cuentas 1718-1789. Valores absolutos

\begin{tabular}{|c|c|c|c|c|c|c|c|c|c|c|c|c|}
\hline & Salarios & Comestibles & $\begin{array}{c}\text { Devolución } \\
\text { prestamos }\end{array}$ & $\begin{array}{l}\text { Actividades } \\
\text { benéficas }\end{array}$ & $\begin{array}{l}\text { Materiales y } \\
\text { enseres }\end{array}$ & $\begin{array}{c}\text { Ganado y su } \\
\text { mantenimiento }\end{array}$ & $\begin{array}{c}\text { Gastos suntuario } \\
\text { y de liturgia }\end{array}$ & Secretaría & Viajes & $\begin{array}{l}\text { Venta de } \\
\text { textiles }\end{array}$ & $\begin{array}{l}\text { Otros } \\
\text { Gastos }\end{array}$ & Totales \\
\hline 1718 & 72 & 2.557 & 1.601 & 0 & 30 & 320 & 79 & 12 & 600 & 457 & 638 & 6.366 \\
\hline 1719 & 19 & 1.324 & & 55 & 586 & 55 & 646 & 130 & 10 & 1.585 & 104 & 4.514 \\
\hline 1720 & 518 & 4.539 & 990 & 75 & 434 & 1.051 & 653 & 88 & 68 & 328 & & 8.744 \\
\hline 1721 & 782 & 4.772 & & & 1.078 & 72 & 203 & 14 & 205 & 4 & 100 & 7.230 \\
\hline 1722 & 1.486 & 943 & & 27 & 655 & 310 & 317 & & 83 & 1.349 & 84 & 5.254 \\
\hline 1723 & 383 & 4.681 & 1.095 & 24 & 288 & 140 & 165 & & & 1.202 & & 7.978 \\
\hline 1724 & 199 & 4.346 & 1.305 & 28 & 222 & 126 & 198 & 9 & & 1.420 & & 7.853 \\
\hline 1725 & & 4.860 & 200 & 5 & 221 & 684 & & & 4 & 1.226 & & 7.200 \\
\hline 1726 & 280 & 5.868 & 0 & 0 & 309 & 0 & 649 & 275 & 556 & 791 & 30 & 8.757 \\
\hline 1727 & 25 & 1.329 & 190 & 19 & & & 80 & 43 & 37 & 1.623 & & 3.346 \\
\hline 1728 & 78 & 4.122 & 60 & 200 & 11 & 340 & & 0 & 300 & 2.710 & 40 & 7.861 \\
\hline 1729 & 241 & 5.934 & & & 185 & 83 & 329 & & 287 & 500 & & 7.559 \\
\hline 1730 & 419 & 4.722 & 0 & 0 & 392 & 122 & 18 & 314 & 152 & 372 & 46 & 6.557 \\
\hline 1731 & 319 & 5.558 & 0 & 0 & 253 & 120 & 362 & 100 & 60 & 896 & 400 & 8.067 \\
\hline 1732 & 1.324 & 4.287 & 0 & 422 & 258 & 662 & 30 & 325 & 361 & 935 & 269 & 8.872 \\
\hline 1733 & 243 & 6.559 & & 32 & 185 & 1.621 & 527 & 70 & 503 & 2.314 & 270 & 12.324 \\
\hline 1734 & 470 & 10.235 & & 98 & 150 & 1.074 & 417 & 46 & 184 & 1.635 & 167 & 14.476 \\
\hline 1735 & 546 & 8.328 & & 12 & 191 & 712 & 1.130 & 48 & 60 & 1.877 & 576 & 13.480 \\
\hline 1736 & 709 & 6.020 & & 407 & 404 & 238 & 714 & 37 & 122 & 1.626 & 4 & 10.281 \\
\hline 1737 & 550 & 3.725 & & 12 & 722 & 900 & 246 & & & 1.130 & 365 & 7.650 \\
\hline 1738 & 643 & 7.790 & 367 & 26 & 129 & 464 & 861 & 69 & 204 & 1.950 & 32 & 12.535 \\
\hline 1739 & 416 & 8.902 & 0 & 6 & 149 & 1.069 & 0 & 437 & 197 & 1.930 & 120 & 13.226 \\
\hline 1740 & 295 & 10.842 & & 9 & 308 & 2.622 & 701 & 82 & 104 & 813 & & 15.776 \\
\hline 1741 & 201 & 7.880 & 22 & 19 & 251 & 576 & 995 & 112 & 96 & 1.087 & 210 & 11.449 \\
\hline 1742 & 267 & 4.343 & 1.466 & 119 & 184 & 63 & 1.132 & 52 & 237 & 1.793 & 6 & 9.662 \\
\hline 1743 & 329 & 6.982 & 0 & 118 & 420 & 148 & 1.150 & 53 & 100 & 1.299 & 8 & 10.607 \\
\hline 1744 & 172 & 8.371 & 1.540 & 298 & 1.108 & 103 & 6 & 89 & 57 & 2.899 & 1.509 & 16.152 \\
\hline 1745 & 507 & 10.594 & 0 & 150 & 330 & 784 & 501 & 84 & 160 & 2.462 & 26 & 15.598 \\
\hline 1746 & 772 & 4.888 & 1 & 131 & 668 & 1.114 & 353 & 181 & 24 & 2.195 & & 10.327 \\
\hline 1747 & 256 & 10.230 & 0 & 25 & 227 & 975 & 1.834 & 229 & 85 & 3.174 & 232 & 17.267 \\
\hline 1748 & 1.532 & 7.647 & 2.650 & 149 & 517 & 720 & 773 & 337 & 50 & 3.035 & 233 & 17.643 \\
\hline 1749 & 1.221 & 7.427 & 331 & 498 & 71 & 323 & 127 & 200 & 8 & 3.105 & 161 & 13.472 \\
\hline 1750 & 2.179 & 11.013 & 2.214 & 196 & 278 & 98 & 792 & 218 & 126 & 3.960 & 342 & 21.416 \\
\hline 1751 & 522 & 9.759 & 332 & 173 & 113 & 673 & 331 & 121 & 60 & 3.898 & 264 & 16.246 \\
\hline 1752 & 923 & 10.593 & 2.650 & 868 & 468 & 125 & 787 & 148 & & 2.898 & 356 & 19.816 \\
\hline 1753 & 1.402 & 7.281 & 4.006 & 769 & 319 & 821 & 688 & 122 & 171 & 3.785 & 284 & 19.648 \\
\hline 1754 & 839 & 14.039 & 1.506 & 1.163 & 489 & 4.906 & 1.158 & 176 & 83 & 4.489 & 576 & 29.424 \\
\hline 1755 & 1.293 & 8.246 & & 1.370 & 814 & 4.261 & 416 & 29 & 85 & 7.667 & 507 & 24.688 \\
\hline 1756 & 1.208 & 14.138 & 750 & 1.235 & 224 & 785 & 981 & 200 & 681 & 4.637 & 504 & 25.343 \\
\hline 1757 & 790 & 8.967 & & 431 & 1.564 & 1.629 & 1.232 & 80 & 53 & 5.685 & 647 & 21.078 \\
\hline 1758 & 913 & 10.626 & 50 & 245 & 170 & 279 & 839 & 113 & 10 & 7.499 & 142 & 20.886 \\
\hline 1759 & 1.141 & 10.509 & & 92 & 789 & 2.326 & 2.839 & 121 & 231 & 6.924 & 896 & 25.868 \\
\hline 1760 & 3.462 & 7.901 & 2.675 & 110 & 3.821 & 450 & 2.333 & 228 & 202 & 5.811 & 656 & 27.649 \\
\hline 1761 & 1.796 & 8.696 & & 84 & 648 & 537 & 2.384 & 303 & 172 & 3.181 & 1.034 & 18.835 \\
\hline 1762 & 4.411 & 7.819 & & 452 & 576 & 46 & 2.685 & 501 & 801 & 4.036 & 650 & 21.977 \\
\hline 1763 & 1.506 & 8.600 & & 390 & 1.343 & 33 & 1.749 & 233 & 399 & 5.430 & 496 & 20.179 \\
\hline 1764 & 1.376 & 14.991 & 0 & 404 & 655 & 2.957 & 1.306 & 357 & 121 & 4.747 & 846 & 27.759 \\
\hline 1765 & 1.178 & 14.501 & 0 & 306 & 997 & 174 & 256 & 838 & 225 & 4.115 & 422 & 23.012 \\
\hline 1766 & 895 & 24.630 & 0 & 282 & 542 & 907 & 543 & 340 & 250 & 3.297 & 586 & 32.272 \\
\hline 1767 & 749 & 11.930 & 0 & 108 & 586 & 518 & 615 & 356 & 241 & 3.427 & 704 & 19.235 \\
\hline 1768 & 842 & 12.186 & & 333 & 314 & 1.440 & 1.910 & 355 & 111 & 3.202 & 896 & 21.589 \\
\hline 1769 & 1.038 & 15.944 & 0 & 0 & 1.658 & 5.144 & 1.017 & 383 & 421 & 4.871 & 748 & 31.224 \\
\hline 1770 & 1.595 & 12.792 & & 240 & 154 & 2.921 & 746 & 70 & 753 & 4.947 & 769 & 24.987 \\
\hline 1771 & 1.299 & 16.033 & 0 & 2 & 1.135 & 130 & 630 & 374 & 145 & 5.302 & 1.128 & 26.178 \\
\hline 1772 & 839 & 10.932 & 0 & 300 & 420 & 1.233 & 1.501 & 296 & 496 & 7.567 & 1.189 & 24.772 \\
\hline 1773 & 1.640 & 19.430 & 0 & 509 & 4.108 & 1.538 & 953 & 472 & 573 & 7.628 & 405 & 37.255 \\
\hline 1774 & 690 & 11.505 & 0 & 810 & 3.949 & 1.389 & 1.650 & 423 & 47 & 6.644 & 862 & 27.967 \\
\hline 1775 & 2.726 & 15.325 & 0 & 1.004 & 2.704 & 742 & 2.641 & 660 & 400 & 9.391 & 995 & 36.587 \\
\hline 1776 & 1.076 & 12.727 & 0 & 1.448 & 505 & 580 & 1.037 & 381 & 98 & 8.122 & 912 & 26.886 \\
\hline 1777 & 1.213 & 14.514 & 80 & 613 & 1.459 & 1.429 & 1.026 & 428 & 145 & 5.102 & 1.345 & 27.353 \\
\hline 1778 & 4.199 & 14.853 & & 476 & 3.748 & 259 & 691 & 390 & 345 & 7.496 & 748 & 33.205 \\
\hline 1779 & 716 & 15.935 & & 295 & 505 & 130 & 764 & 358 & 185 & 8.708 & 1.386 & 28.982 \\
\hline 1780 & 5.093 & 12.669 & 20 & 721 & 645 & 96 & 1.076 & 811 & 304 & 9.366 & 606 & 31.407 \\
\hline 1781 & 644 & 14.212 & 400 & 1.404 & 726 & 97 & 2.045 & 336 & 773 & 8.652 & 1.451 & 30.740 \\
\hline 1782 & 1.578 & 16.539 & & 1.275 & 2.330 & 1.357 & 405 & 484 & 691 & 7.869 & 133 & 32.660 \\
\hline 1783 & 3.207 & 13.553 & & 3.945 & 4.356 & 1.604 & 1.689 & 434 & 640 & 9.028 & 576 & 39.032 \\
\hline 1784 & 2.166 & 21.009 & & 3.053 & 1.658 & 3.790 & 729 & 837 & 704 & 13.465 & 810 & 48.221 \\
\hline 1785 & 1.916 & 20.011 & 0 & 1.009 & 1.464 & 2.442 & 2.343 & 1.171 & 627 & 9.795 & 828 & 41.605 \\
\hline 1786 & 872 & 15.774 & 0 & 550 & 188 & 1.878 & 594 & 949 & 89 & 1.405 & 778 & 23.077 \\
\hline 1787 & 1.284 & 15.071 & 0 & 794 & 1.608 & 516 & 3.933 & 597 & 127 & 1.468 & 646 & 26.044 \\
\hline 1788 & 1.484 & 15.770 & 0 & 2.109 & 1.435 & 315 & 4.988 & 360 & 258 & 8.226 & 948 & 35.892 \\
\hline 1789 & 753 & 9.466 & 0 & 192 & 26 & 0 & 177 & 199 & 20 & 8.831 & 797 & 20.461 \\
\hline
\end{tabular}


Tabla 3. Ingresos registrados en el Libro de cuentas 1718-1789. Valores relativos

\begin{tabular}{|c|c|c|c|c|c|c|c|c|c|c|}
\hline & Limosnas & Feria & Misas & $\begin{array}{c}\text { Ventas } \\
\text { comestibles }\end{array}$ & $\begin{array}{l}\text { Ventas } \\
\text { textiles }\end{array}$ & $\begin{array}{c}\text { Ganado } \\
\text { y sebo }\end{array}$ & Reintegros & Donaciones & Préstamos & Otros \\
\hline 1718 & $38 \%$ & $10 \%$ & $10 \%$ & $24 \%$ & $5 \%$ & $8 \%$ & $0 \%$ & $0 \%$ & $0 \%$ & $5 \%$ \\
\hline 1719 & $32 \%$ & $9 \%$ & $7 \%$ & $27 \%$ & $8 \%$ & $17 \%$ & $0 \%$ & $0 \%$ & $0 \%$ & $0 \%$ \\
\hline 1720 & $38 \%$ & $13 \%$ & $4 \%$ & $31 \%$ & $5 \%$ & $7 \%$ & $1 \%$ & $0 \%$ & $0 \%$ & $1 \%$ \\
\hline 1721 & $18 \%$ & $3 \%$ & $16 \%$ & $40 \%$ & $2 \%$ & $11 \%$ & $1 \%$ & $0 \%$ & $0 \%$ & $8 \%$ \\
\hline 1722 & $26 \%$ & $24 \%$ & $19 \%$ & $25 \%$ & $0 \%$ & $2 \%$ & $3 \%$ & $0 \%$ & $0 \%$ & $1 \%$ \\
\hline 1723 & $40 \%$ & $11 \%$ & $32 \%$ & $0 \%$ & $1 \%$ & $2 \%$ & $5 \%$ & $0 \%$ & $0 \%$ & $10 \%$ \\
\hline 1724 & $42 \%$ & $9 \%$ & $23 \%$ & $12 \%$ & $1 \%$ & $5 \%$ & $0 \%$ & $0 \%$ & $0 \%$ & $9 \%$ \\
\hline 1725 & $32 \%$ & $13 \%$ & $19 \%$ & $26 \%$ & $2 \%$ & $0 \%$ & $7 \%$ & $0 \%$ & $0 \%$ & $2 \%$ \\
\hline 1726 & $56 \%$ & $18 \%$ & $15 \%$ & $0 \%$ & $2 \%$ & $9 \%$ & $0 \%$ & $0 \%$ & $0 \%$ & $0 \%$ \\
\hline 1727 & $22 \%$ & $29 \%$ & $19 \%$ & $5 \%$ & $7 \%$ & $0 \%$ & $0 \%$ & $0 \%$ & $0 \%$ & $18 \%$ \\
\hline 1728 & $14 \%$ & $8 \%$ & $29 \%$ & $37 \%$ & $11 \%$ & $0 \%$ & $1 \%$ & $0 \%$ & $0 \%$ & $0 \%$ \\
\hline 1729 & $33 \%$ & $10 \%$ & $24 \%$ & $10 \%$ & $11 \%$ & $0 \%$ & $10 \%$ & $0 \%$ & $0 \%$ & $2 \%$ \\
\hline 1730 & $38 \%$ & $10 \%$ & $8 \%$ & $26 \%$ & $13 \%$ & $4 \%$ & $2 \%$ & $0 \%$ & $0 \%$ & $0 \%$ \\
\hline 1731 & $30 \%$ & $7 \%$ & $27 \%$ & $10 \%$ & $14 \%$ & $8 \%$ & $5 \%$ & $0 \%$ & $0 \%$ & $0 \%$ \\
\hline 1732 & $43 \%$ & $8 \%$ & $12 \%$ & $11 \%$ & $15 \%$ & $12 \%$ & $0 \%$ & $0 \%$ & $0 \%$ & $0 \%$ \\
\hline 1733 & $18 \%$ & $2 \%$ & $21 \%$ & $34 \%$ & $8 \%$ & $16 \%$ & $0 \%$ & $0 \%$ & $0 \%$ & $0 \%$ \\
\hline 1734 & $27 \%$ & $0 \%$ & $28 \%$ & $9 \%$ & $7 \%$ & $0 \%$ & $1 \%$ & $0 \%$ & $27 \%$ & $0 \%$ \\
\hline 1735 & $30 \%$ & $4 \%$ & $26 \%$ & $15 \%$ & $5 \%$ & $1 \%$ & $0 \%$ & $0 \%$ & $20 \%$ & $0 \%$ \\
\hline 1736 & $21 \%$ & $7 \%$ & $24 \%$ & $39 \%$ & $5 \%$ & $5 \%$ & $0 \%$ & $0 \%$ & $0 \%$ & $0 \%$ \\
\hline 1737 & $17 \%$ & $5 \%$ & $15 \%$ & $41 \%$ & $1 \%$ & $2 \%$ & $20 \%$ & $0 \%$ & $0 \%$ & $0 \%$ \\
\hline 1738 & $22 \%$ & $4 \%$ & $30 \%$ & $21 \%$ & $1 \%$ & $12 \%$ & $0 \%$ & $0 \%$ & $0 \%$ & $10 \%$ \\
\hline 1739 & $31 \%$ & $8 \%$ & $18 \%$ & $28 \%$ & $4 \%$ & $5 \%$ & $0 \%$ & $0 \%$ & $0 \%$ & $6 \%$ \\
\hline 1740 & $15 \%$ & $7 \%$ & $8 \%$ & $22 \%$ & $16 \%$ & $14 \%$ & $19 \%$ & $0 \%$ & $0 \%$ & $0 \%$ \\
\hline 1741 & $5 \%$ & $5 \%$ & $18 \%$ & $38 \%$ & $8 \%$ & $19 \%$ & $0 \%$ & $0 \%$ & $0 \%$ & $6 \%$ \\
\hline 1742 & $34 \%$ & $11 \%$ & $18 \%$ & $20 \%$ & $6 \%$ & $3 \%$ & $5 \%$ & $0 \%$ & $0 \%$ & $3 \%$ \\
\hline 1743 & $7 \%$ & $15 \%$ & $29 \%$ & $41 \%$ & $6 \%$ & $2 \%$ & $0 \%$ & $0 \%$ & $0 \%$ & $0 \%$ \\
\hline 1744 & $2 \%$ & $8 \%$ & $56 \%$ & $13 \%$ & $9 \%$ & $1 \%$ & $4 \%$ & $0 \%$ & $7 \%$ & $0 \%$ \\
\hline 1745 & $7 \%$ & $14 \%$ & $24 \%$ & $38 \%$ & $5 \%$ & $11 \%$ & $0 \%$ & $0 \%$ & $0 \%$ & $0 \%$ \\
\hline 1746 & $5 \%$ & $42 \%$ & $18 \%$ & $8 \%$ & $1 \%$ & $19 \%$ & $0 \%$ & $3 \%$ & $0 \%$ & $2 \%$ \\
\hline 1747 & $6 \%$ & $2 \%$ & $26 \%$ & $24 \%$ & $10 \%$ & $20 \%$ & $0 \%$ & $0 \%$ & $0 \%$ & $12 \%$ \\
\hline 1748 & $9 \%$ & $6 \%$ & $16 \%$ & $16 \%$ & $6 \%$ & $3 \%$ & $0 \%$ & $0 \%$ & $43 \%$ & $0 \%$ \\
\hline 1749 & $5 \%$ & $15 \%$ & $19 \%$ & $35 \%$ & $9 \%$ & $8 \%$ & $2 \%$ & $8 \%$ & $0 \%$ & $0 \%$ \\
\hline 1750 & $7 \%$ & $9 \%$ & $13 \%$ & $9 \%$ & $6 \%$ & $2 \%$ & $0 \%$ & $0 \%$ & $18 \%$ & $38 \%$ \\
\hline 1751 & $3 \%$ & $12 \%$ & $31 \%$ & $39 \%$ & $10 \%$ & $2 \%$ & $0 \%$ & $2 \%$ & $0 \%$ & $2 \%$ \\
\hline 1752 & $5 \%$ & $12 \%$ & $37 \%$ & $26 \%$ & $3 \%$ & $1 \%$ & $0 \%$ & $0 \%$ & $0 \%$ & $16 \%$ \\
\hline 1753 & $6 \%$ & $15 \%$ & $26 \%$ & $29 \%$ & $4 \%$ & $11 \%$ & $0 \%$ & $0 \%$ & $0 \%$ & $10 \%$ \\
\hline 1754 & $2 \%$ & $14 \%$ & $20 \%$ & $41 \%$ & $4 \%$ & $6 \%$ & $0 \%$ & $0 \%$ & $0 \%$ & $12 \%$ \\
\hline 1755 & $6 \%$ & $15 \%$ & $32 \%$ & $18 \%$ & $16 \%$ & $4 \%$ & $0 \%$ & $0 \%$ & $0 \%$ & $9 \%$ \\
\hline 1756 & $15 \%$ & $12 \%$ & $30 \%$ & $14 \%$ & $7 \%$ & $12 \%$ & $0 \%$ & $1 \%$ & $0 \%$ & $9 \%$ \\
\hline 1757 & $18 \%$ & $13 \%$ & $29 \%$ & $10 \%$ & $4 \%$ & $5 \%$ & $0 \%$ & $1 \%$ & $12 \%$ & $7 \%$ \\
\hline 1758 & $3 \%$ & $13 \%$ & $30 \%$ & $11 \%$ & $15 \%$ & $9 \%$ & $0 \%$ & $1 \%$ & $7 \%$ & $10 \%$ \\
\hline 1759 & $6 \%$ & $12 \%$ & $33 \%$ & $13 \%$ & $18 \%$ & $1 \%$ & $0 \%$ & $3 \%$ & $0 \%$ & $14 \%$ \\
\hline 1760 & $7 \%$ & $12 \%$ & $25 \%$ & $23 \%$ & $11 \%$ & $0 \%$ & $0 \%$ & $13 \%$ & $0 \%$ & $9 \%$ \\
\hline 1761 & $4 \%$ & $20 \%$ & $47 \%$ & $14 \%$ & $7 \%$ & $4 \%$ & $0 \%$ & $1 \%$ & $0 \%$ & $3 \%$ \\
\hline 1762 & $15 \%$ & $19 \%$ & $24 \%$ & $16 \%$ & $10 \%$ & $9 \%$ & $3 \%$ & $4 \%$ & $0 \%$ & $0 \%$ \\
\hline 1763 & $15 \%$ & $7 \%$ & $29 \%$ & $28 \%$ & $6 \%$ & $13 \%$ & $0 \%$ & $1 \%$ & $0 \%$ & $2 \%$ \\
\hline 1764 & $22 \%$ & $7 \%$ & $28 \%$ & $35 \%$ & $4 \%$ & $4 \%$ & $0 \%$ & $0 \%$ & $0 \%$ & $0 \%$ \\
\hline 1765 & $10 \%$ & $10 \%$ & $21 \%$ & $18 \%$ & $14 \%$ & $10 \%$ & $0 \%$ & $16 \%$ & $0 \%$ & $0 \%$ \\
\hline 1766 & $20 \%$ & $20 \%$ & $17 \%$ & $35 \%$ & $4 \%$ & $2 \%$ & $0 \%$ & $1 \%$ & $0 \%$ & $0 \%$ \\
\hline 1767 & $12 \%$ & $16 \%$ & $39 \%$ & $13 \%$ & $10 \%$ & $11 \%$ & $0 \%$ & $0 \%$ & $0 \%$ & $0 \%$ \\
\hline 1768 & $9 \%$ & $8 \%$ & $44 \%$ & $17 \%$ & $17 \%$ & $4 \%$ & $0 \%$ & $0 \%$ & $0 \%$ & $1 \%$ \\
\hline 1769 & $9 \%$ & $15 \%$ & $29 \%$ & $26 \%$ & $10 \%$ & $10 \%$ & $0 \%$ & $0 \%$ & $0 \%$ & $1 \%$ \\
\hline 1770 & $2 \%$ & $12 \%$ & $30 \%$ & $39 \%$ & $10 \%$ & $5 \%$ & $0 \%$ & $0 \%$ & $0 \%$ & $4 \%$ \\
\hline 1771 & $2 \%$ & $11 \%$ & $47 \%$ & $21 \%$ & $10 \%$ & $7 \%$ & $0 \%$ & $0 \%$ & $0 \%$ & $2 \%$ \\
\hline 1772 & $6 \%$ & $11 \%$ & $45 \%$ & $29 \%$ & $6 \%$ & $3 \%$ & $0 \%$ & $0 \%$ & $0 \%$ & $0 \%$ \\
\hline 1773 & $5 \%$ & $8 \%$ & $26 \%$ & $23 \%$ & $10 \%$ & $29 \%$ & $0 \%$ & $0 \%$ & $0 \%$ & $0 \%$ \\
\hline 1774 & $3 \%$ & $9 \%$ & $37 \%$ & $30 \%$ & $16 \%$ & $4 \%$ & $0 \%$ & $0 \%$ & $0 \%$ & $0 \%$ \\
\hline 1775 & $5 \%$ & $8 \%$ & $53 \%$ & $12 \%$ & $7 \%$ & $15 \%$ & $0 \%$ & $0 \%$ & $0 \%$ & $0 \%$ \\
\hline 1776 & $7 \%$ & $15 \%$ & $46 \%$ & $15 \%$ & $17 \%$ & $1 \%$ & $0 \%$ & $0 \%$ & $0 \%$ & $0 \%$ \\
\hline 1777 & $20 \%$ & $14 \%$ & $31 \%$ & $29 \%$ & $6 \%$ & $0 \%$ & $0 \%$ & $0 \%$ & $0 \%$ & $0 \%$ \\
\hline 1778 & $13 \%$ & $6 \%$ & $35 \%$ & $26 \%$ & $13 \%$ & $5 \%$ & $2 \%$ & $0 \%$ & $0 \%$ & $0 \%$ \\
\hline 1779 & $5 \%$ & $8 \%$ & $38 \%$ & $21 \%$ & $6 \%$ & $23 \%$ & $0 \%$ & $0 \%$ & $0 \%$ & $0 \%$ \\
\hline 1780 & $6 \%$ & $9 \%$ & $40 \%$ & $13 \%$ & $23 \%$ & $8 \%$ & $0 \%$ & $0 \%$ & $0 \%$ & $0 \%$ \\
\hline 1781 & $3 \%$ & $8 \%$ & $47 \%$ & $16 \%$ & $18 \%$ & $7 \%$ & $1 \%$ & $1 \%$ & $0 \%$ & $0 \%$ \\
\hline 1782 & $14 \%$ & $10 \%$ & $35 \%$ & $19 \%$ & $10 \%$ & $9 \%$ & $3 \%$ & $0 \%$ & $0 \%$ & $0 \%$ \\
\hline 1783 & $9 \%$ & $0 \%$ & $29 \%$ & $28 \%$ & $20 \%$ & $14 \%$ & $0 \%$ & $0 \%$ & $0 \%$ & $0 \%$ \\
\hline 1784 & $5 \%$ & $0 \%$ & $36 \%$ & $39 \%$ & $9 \%$ & $11 \%$ & $0 \%$ & $0 \%$ & $0 \%$ & $1 \%$ \\
\hline 1785 & $12 \%$ & $0 \%$ & $29 \%$ & $34 \%$ & $14 \%$ & $12 \%$ & $0 \%$ & $0 \%$ & $0 \%$ & $0 \%$ \\
\hline 1786 & $9 \%$ & $0 \%$ & $26 \%$ & $51 \%$ & $7 \%$ & $3 \%$ & $1 \%$ & $1 \%$ & $0 \%$ & $0 \%$ \\
\hline 1787 & $4 \%$ & $0 \%$ & $51 \%$ & $28 \%$ & $14 \%$ & $1 \%$ & $1 \%$ & $0 \%$ & $0 \%$ & $0 \%$ \\
\hline 1788 & $8 \%$ & $0 \%$ & $46 \%$ & $23 \%$ & $17 \%$ & $6 \%$ & $0 \%$ & $0 \%$ & $0 \%$ & $0 \%$ \\
\hline 1789 & $5 \%$ & $0 \%$ & $30 \%$ & $18 \%$ & $20 \%$ & $26 \%$ & $2 \%$ & $0 \%$ & $0 \%$ & $0 \%$ \\
\hline
\end{tabular}


Tabla 4. Gastos registrados en el Libro de cuentas 1718-1789. Valores relativos

\begin{tabular}{|c|c|c|c|c|c|c|c|c|c|c|c|}
\hline & Salarios & Comestibles & $\begin{array}{c}\text { Devolución } \\
\text { prestamos }\end{array}$ & $\begin{array}{l}\text { Actividades } \\
\text { benéficas }\end{array}$ & $\begin{array}{l}\text { Materiales } \\
\text { y enseres }\end{array}$ & $\begin{array}{c}\text { Ganado y su } \\
\text { mantenimiento }\end{array}$ & $\begin{array}{c}\text { Gastos suntuarios } \\
\text { y de liturgia }\end{array}$ & Secretaría & Viajes & $\begin{array}{l}\text { Venta de } \\
\text { textiles }\end{array}$ & $\begin{array}{l}\text { Otros } \\
\text { Gastos }\end{array}$ \\
\hline 1718 & $1 \%$ & $40 \%$ & $25 \%$ & $0 \%$ & $0 \%$ & $5 \%$ & $1 \%$ & $0 \%$ & $9 \%$ & $7 \%$ & $10 \%$ \\
\hline 1719 & $0 \%$ & $29 \%$ & $0 \%$ & $1 \%$ & $13 \%$ & $1 \%$ & $14 \%$ & $3 \%$ & $0 \%$ & $35 \%$ & $2 \%$ \\
\hline 1720 & $6 \%$ & $52 \%$ & $11 \%$ & $1 \%$ & $5 \%$ & $12 \%$ & $7 \%$ & $1 \%$ & $1 \%$ & $4 \%$ & $0 \%$ \\
\hline 1721 & $11 \%$ & $66 \%$ & $0 \%$ & $0 \%$ & $15 \%$ & $1 \%$ & $3 \%$ & $0 \%$ & $3 \%$ & $0 \%$ & $1 \%$ \\
\hline 1722 & $28 \%$ & $18 \%$ & $0 \%$ & $1 \%$ & $12 \%$ & $6 \%$ & $6 \%$ & $0 \%$ & $2 \%$ & $26 \%$ & $2 \%$ \\
\hline 1723 & $5 \%$ & $59 \%$ & $14 \%$ & $0 \%$ & $4 \%$ & $2 \%$ & $2 \%$ & $0 \%$ & $0 \%$ & $15 \%$ & $0 \%$ \\
\hline 1724 & $3 \%$ & $55 \%$ & $17 \%$ & $0 \%$ & $3 \%$ & $2 \%$ & $3 \%$ & $0 \%$ & $0 \%$ & $18 \%$ & 0\% \\
\hline 1725 & $0 \%$ & $68 \%$ & $3 \%$ & $0 \%$ & $3 \%$ & $10 \%$ & $0 \%$ & $0 \%$ & $0 \%$ & $17 \%$ & $0 \%$ \\
\hline 1726 & $3 \%$ & $67 \%$ & $0 \%$ & $0 \%$ & $4 \%$ & $0 \%$ & $7 \%$ & $3 \%$ & $6 \%$ & $9 \%$ & 0\% \\
\hline 1727 & $1 \%$ & $40 \%$ & $6 \%$ & $1 \%$ & $0 \%$ & $0 \%$ & $2 \%$ & $1 \%$ & $1 \%$ & $49 \%$ & 0\% \\
\hline 1728 & $1 \%$ & $52 \%$ & $1 \%$ & $3 \%$ & $0 \%$ & $4 \%$ & $0 \%$ & $0 \%$ & $4 \%$ & $34 \%$ & $1 \%$ \\
\hline 1729 & $3 \%$ & $79 \%$ & $0 \%$ & $0 \%$ & $2 \%$ & $1 \%$ & $4 \%$ & $0 \%$ & $4 \%$ & $7 \%$ & $0 \%$ \\
\hline 1730 & $6 \%$ & $72 \%$ & $0 \%$ & $0 \%$ & $6 \%$ & $2 \%$ & $0 \%$ & $5 \%$ & $2 \%$ & $6 \%$ & $1 \%$ \\
\hline 1731 & $4 \%$ & $69 \%$ & $0 \%$ & $0 \%$ & $3 \%$ & $1 \%$ & $4 \%$ & $1 \%$ & $1 \%$ & $11 \%$ & $5 \%$ \\
\hline 1732 & $15 \%$ & $48 \%$ & $0 \%$ & $5 \%$ & $3 \%$ & $7 \%$ & $0 \%$ & $4 \%$ & $4 \%$ & $11 \%$ & $3 \%$ \\
\hline 1733 & $2 \%$ & $53 \%$ & $0 \%$ & $0 \%$ & $2 \%$ & $13 \%$ & $4 \%$ & $1 \%$ & $4 \%$ & $19 \%$ & $2 \%$ \\
\hline 1734 & $3 \%$ & $71 \%$ & $0 \%$ & $1 \%$ & $1 \%$ & $7 \%$ & $3 \%$ & $0 \%$ & $1 \%$ & $11 \%$ & $1 \%$ \\
\hline 1735 & $4 \%$ & $62 \%$ & $0 \%$ & $0 \%$ & $1 \%$ & $5 \%$ & $8 \%$ & $0 \%$ & $0 \%$ & $14 \%$ & $4 \%$ \\
\hline 1736 & $7 \%$ & $59 \%$ & $0 \%$ & $4 \%$ & $4 \%$ & $2 \%$ & $7 \%$ & $0 \%$ & $1 \%$ & $16 \%$ & $0 \%$ \\
\hline 1737 & $7 \%$ & $49 \%$ & $0 \%$ & $0 \%$ & $9 \%$ & $12 \%$ & $3 \%$ & $0 \%$ & $0 \%$ & $15 \%$ & $5 \%$ \\
\hline 1738 & $5 \%$ & $62 \%$ & $3 \%$ & $0 \%$ & $1 \%$ & $4 \%$ & $7 \%$ & $1 \%$ & $2 \%$ & $16 \%$ & $0 \%$ \\
\hline 1739 & $3 \%$ & $67 \%$ & $0 \%$ & $0 \%$ & $1 \%$ & $8 \%$ & $0 \%$ & $3 \%$ & $1 \%$ & $15 \%$ & $1 \%$ \\
\hline 1740 & $2 \%$ & $69 \%$ & $0 \%$ & $0 \%$ & $2 \%$ & $17 \%$ & $4 \%$ & $1 \%$ & $1 \%$ & $5 \%$ & $0 \%$ \\
\hline 1741 & $2 \%$ & $69 \%$ & $0 \%$ & $0 \%$ & $2 \%$ & $5 \%$ & $9 \%$ & $1 \%$ & $1 \%$ & $9 \%$ & $2 \%$ \\
\hline 1742 & $3 \%$ & $45 \%$ & $15 \%$ & $1 \%$ & $2 \%$ & $1 \%$ & $12 \%$ & $1 \%$ & $2 \%$ & $19 \%$ & $0 \%$ \\
\hline 1743 & $3 \%$ & $66 \%$ & $0 \%$ & $1 \%$ & $4 \%$ & $1 \%$ & $11 \%$ & $0 \%$ & $1 \%$ & $12 \%$ & $0 \%$ \\
\hline 1744 & $1 \%$ & $52 \%$ & $10 \%$ & $2 \%$ & $7 \%$ & $1 \%$ & $0 \%$ & $1 \%$ & $0 \%$ & $18 \%$ & $9 \%$ \\
\hline 1745 & $3 \%$ & $68 \%$ & $0 \%$ & $1 \%$ & $2 \%$ & $5 \%$ & $3 \%$ & $1 \%$ & $1 \%$ & $16 \%$ & $0 \%$ \\
\hline 1746 & $7 \%$ & $47 \%$ & $0 \%$ & $1 \%$ & $6 \%$ & $11 \%$ & $3 \%$ & $2 \%$ & $0 \%$ & $21 \%$ & $0 \%$ \\
\hline 1747 & $1 \%$ & $59 \%$ & $0 \%$ & $0 \%$ & $1 \%$ & $6 \%$ & $11 \%$ & $1 \%$ & $0 \%$ & $18 \%$ & $1 \%$ \\
\hline 1748 & $9 \%$ & $43 \%$ & $15 \%$ & $1 \%$ & $3 \%$ & $4 \%$ & $4 \%$ & $2 \%$ & $0 \%$ & $17 \%$ & $1 \%$ \\
\hline 1749 & $9 \%$ & $55 \%$ & $2 \%$ & $4 \%$ & $1 \%$ & $2 \%$ & $1 \%$ & $1 \%$ & $0 \%$ & $23 \%$ & $1 \%$ \\
\hline 1750 & $10 \%$ & $51 \%$ & $10 \%$ & $1 \%$ & $1 \%$ & $0 \%$ & $4 \%$ & $1 \%$ & $1 \%$ & $18 \%$ & $2 \%$ \\
\hline 1751 & $3 \%$ & $60 \%$ & $2 \%$ & $1 \%$ & $1 \%$ & $4 \%$ & $2 \%$ & $1 \%$ & $0 \%$ & $24 \%$ & $2 \%$ \\
\hline 1752 & $5 \%$ & $53 \%$ & $13 \%$ & $4 \%$ & $2 \%$ & $1 \%$ & $4 \%$ & $1 \%$ & $0 \%$ & $15 \%$ & $2 \%$ \\
\hline 1753 & $7 \%$ & $37 \%$ & $20 \%$ & $4 \%$ & $2 \%$ & $4 \%$ & $4 \%$ & $1 \%$ & $1 \%$ & $19 \%$ & $1 \%$ \\
\hline 1754 & $3 \%$ & $48 \%$ & $5 \%$ & $4 \%$ & $2 \%$ & $17 \%$ & $4 \%$ & $1 \%$ & $0 \%$ & $15 \%$ & $2 \%$ \\
\hline 1755 & $5 \%$ & $33 \%$ & $0 \%$ & $6 \%$ & $3 \%$ & $17 \%$ & $2 \%$ & $0 \%$ & $0 \%$ & $31 \%$ & $2 \%$ \\
\hline 1756 & $5 \%$ & $56 \%$ & $3 \%$ & $5 \%$ & $1 \%$ & $3 \%$ & $4 \%$ & $1 \%$ & $3 \%$ & $18 \%$ & $2 \%$ \\
\hline 1757 & $4 \%$ & $43 \%$ & $0 \%$ & $2 \%$ & $7 \%$ & $8 \%$ & $6 \%$ & $0 \%$ & $0 \%$ & $27 \%$ & $3 \%$ \\
\hline 1758 & $4 \%$ & $51 \%$ & $0 \%$ & $1 \%$ & $1 \%$ & $1 \%$ & $4 \%$ & $1 \%$ & $0 \%$ & $36 \%$ & $1 \%$ \\
\hline 1759 & $4 \%$ & $41 \%$ & $0 \%$ & $0 \%$ & $3 \%$ & $9 \%$ & $11 \%$ & $0 \%$ & $1 \%$ & $27 \%$ & $3 \%$ \\
\hline 1760 & $13 \%$ & $29 \%$ & $10 \%$ & $0 \%$ & $14 \%$ & $2 \%$ & $8 \%$ & $1 \%$ & $1 \%$ & $21 \%$ & $2 \%$ \\
\hline 1761 & $10 \%$ & $46 \%$ & $0 \%$ & $0 \%$ & $3 \%$ & $3 \%$ & $13 \%$ & $2 \%$ & $1 \%$ & $17 \%$ & $5 \%$ \\
\hline 1762 & $20 \%$ & $36 \%$ & $0 \%$ & $2 \%$ & $3 \%$ & $0 \%$ & $12 \%$ & $2 \%$ & $4 \%$ & $18 \%$ & $3 \%$ \\
\hline 1763 & $7 \%$ & $43 \%$ & $0 \%$ & $2 \%$ & $7 \%$ & $0 \%$ & $9 \%$ & $1 \%$ & $2 \%$ & $27 \%$ & $2 \%$ \\
\hline 1764 & $5 \%$ & $54 \%$ & $0 \%$ & $1 \%$ & $2 \%$ & $11 \%$ & $5 \%$ & $1 \%$ & $0 \%$ & $17 \%$ & $3 \%$ \\
\hline 1765 & $5 \%$ & $63 \%$ & $0 \%$ & $1 \%$ & $4 \%$ & $1 \%$ & $1 \%$ & $4 \%$ & $1 \%$ & $18 \%$ & $2 \%$ \\
\hline 1766 & $3 \%$ & $76 \%$ & $0 \%$ & $1 \%$ & $2 \%$ & $3 \%$ & $2 \%$ & $1 \%$ & $1 \%$ & $10 \%$ & $2 \%$ \\
\hline 1767 & $4 \%$ & $62 \%$ & $0 \%$ & $1 \%$ & $3 \%$ & $3 \%$ & $3 \%$ & $2 \%$ & $1 \%$ & $18 \%$ & $4 \%$ \\
\hline 1768 & $4 \%$ & $56 \%$ & $0 \%$ & $2 \%$ & $1 \%$ & $7 \%$ & $9 \%$ & $2 \%$ & $1 \%$ & $15 \%$ & $4 \%$ \\
\hline 1769 & $3 \%$ & $51 \%$ & $0 \%$ & $0 \%$ & $5 \%$ & $16 \%$ & $3 \%$ & $1 \%$ & $1 \%$ & $16 \%$ & $2 \%$ \\
\hline 1770 & $6 \%$ & $51 \%$ & $0 \%$ & $1 \%$ & $1 \%$ & $12 \%$ & $3 \%$ & $0 \%$ & $3 \%$ & $20 \%$ & $3 \%$ \\
\hline 1771 & $5 \%$ & $61 \%$ & $0 \%$ & $0 \%$ & $4 \%$ & $0 \%$ & $2 \%$ & $1 \%$ & $1 \%$ & $20 \%$ & $4 \%$ \\
\hline 1772 & $3 \%$ & $44 \%$ & $0 \%$ & $1 \%$ & $2 \%$ & $5 \%$ & $6 \%$ & $1 \%$ & $2 \%$ & $31 \%$ & $5 \%$ \\
\hline 1773 & $4 \%$ & $52 \%$ & $0 \%$ & $1 \%$ & $11 \%$ & $4 \%$ & $3 \%$ & $1 \%$ & $2 \%$ & $20 \%$ & $1 \%$ \\
\hline 1774 & $2 \%$ & $41 \%$ & $0 \%$ & $3 \%$ & $14 \%$ & $5 \%$ & $6 \%$ & $2 \%$ & $0 \%$ & $24 \%$ & $3 \%$ \\
\hline 1775 & $7 \%$ & $42 \%$ & $0 \%$ & $3 \%$ & $7 \%$ & $2 \%$ & $7 \%$ & $2 \%$ & $1 \%$ & $26 \%$ & $3 \%$ \\
\hline 1776 & $4 \%$ & $47 \%$ & $0 \%$ & $5 \%$ & $2 \%$ & $2 \%$ & $4 \%$ & $1 \%$ & $0 \%$ & $30 \%$ & $3 \%$ \\
\hline 1777 & $4 \%$ & $53 \%$ & $0 \%$ & $2 \%$ & $5 \%$ & $5 \%$ & $4 \%$ & $2 \%$ & $1 \%$ & $19 \%$ & $5 \%$ \\
\hline 1778 & $13 \%$ & $45 \%$ & $0 \%$ & $1 \%$ & $11 \%$ & $1 \%$ & $2 \%$ & $1 \%$ & $1 \%$ & $23 \%$ & $2 \%$ \\
\hline 1779 & $2 \%$ & $55 \%$ & $0 \%$ & $1 \%$ & $2 \%$ & $0 \%$ & $3 \%$ & $1 \%$ & $1 \%$ & $30 \%$ & $5 \%$ \\
\hline 1780 & $16 \%$ & $40 \%$ & $0 \%$ & $2 \%$ & $2 \%$ & $0 \%$ & $3 \%$ & $3 \%$ & $1 \%$ & $30 \%$ & $2 \%$ \\
\hline 1781 & $2 \%$ & $46 \%$ & $1 \%$ & $5 \%$ & $2 \%$ & $0 \%$ & $7 \%$ & $1 \%$ & $3 \%$ & $28 \%$ & $5 \%$ \\
\hline 1782 & $5 \%$ & $51 \%$ & $0 \%$ & $4 \%$ & $7 \%$ & $4 \%$ & $1 \%$ & $1 \%$ & $2 \%$ & $24 \%$ & $0 \%$ \\
\hline 1783 & $8 \%$ & $35 \%$ & $0 \%$ & $10 \%$ & $11 \%$ & $4 \%$ & $4 \%$ & $1 \%$ & $2 \%$ & $23 \%$ & $1 \%$ \\
\hline 1784 & $4 \%$ & $44 \%$ & $0 \%$ & $6 \%$ & $3 \%$ & $8 \%$ & $2 \%$ & $2 \%$ & $1 \%$ & $28 \%$ & $2 \%$ \\
\hline 1785 & $5 \%$ & $48 \%$ & $0 \%$ & $2 \%$ & $4 \%$ & $6 \%$ & $6 \%$ & $3 \%$ & $2 \%$ & $24 \%$ & $2 \%$ \\
\hline 1786 & $4 \%$ & $68 \%$ & $0 \%$ & $2 \%$ & $1 \%$ & $8 \%$ & $3 \%$ & $4 \%$ & $0 \%$ & $6 \%$ & $3 \%$ \\
\hline 1787 & $5 \%$ & $58 \%$ & $0 \%$ & $3 \%$ & $6 \%$ & $2 \%$ & $15 \%$ & $2 \%$ & $0 \%$ & $6 \%$ & $2 \%$ \\
\hline 1788 & $4 \%$ & $44 \%$ & $0 \%$ & $6 \%$ & $4 \%$ & $1 \%$ & $14 \%$ & $1 \%$ & $1 \%$ & $23 \%$ & $3 \%$ \\
\hline 1789 & $4 \%$ & $46 \%$ & $0 \%$ & $1 \%$ & $0 \%$ & $0 \%$ & $1 \%$ & $1 \%$ & $0 \%$ & $43 \%$ & $4 \%$ \\
\hline
\end{tabular}


Tabla 5. Precios promedios

\begin{tabular}{|c|c|c|c|c|c|c|c|c|c|c|c|c|c|c|c|c|c|c|c|}
\hline & Vino & zzúcé & escad & Sal & aca & Higos & Garbanzos & Miel & Canela & Aceite & Almendra & Clavo & Cebada & Arroz & Dulces & Anises & Avena & Pasas & Huevos \\
\hline 1760 & & 86 & 27 & 22 & 8 & & 10 & & 65 & 14 & 30 & 9 & & 11 & 11 & & & & \\
\hline 1761 & 8 & 76 & 27 & & 8 & 24 & 10 & 25 & 48 & 21 & 34 & 4 & & & 5 & & & & \\
\hline 1762 & 6 & 75 & 28 & 21 & 9 & 24 & 11 & 30 & 54 & 17 & 36 & & & 16 & 5 & & & & \\
\hline 1763 & 5 & 81 & 30 & 24 & 9 & & 13 & 25 & 57 & 14 & & & & 15 & 6 & 6 & & 50 & 1 \\
\hline 1764 & 4 & 68 & & & 7 & & & & 64 & & & & & & & & & & \\
\hline 1765 & 4 & 65 & 28 & 22 & 7 & 27 & & & 59 & 30 & 49 & 4 & 23 & 16 & 5 & 5 & 13 & 70 & 2 \\
\hline 1766 & 11 & 73 & 31 & & 7 & 26 & 14 & & 64 & 40 & 27 & 4 & 9 & 17 & 5 & 4 & & & 4 \\
\hline 1767 & 5 & 73 & 41 & & 8 & 25 & & & 64 & 23 & & & & & 5 & 5 & & 60 & \\
\hline 1768 & & 65 & 24 & 26 & 9 & & 13 & & 60 & 32 & 37 & 8 & 17 & 14 & 6 & 4 & 10 & & 2 \\
\hline 1769 & 5 & 67 & 29 & & 9 & 33 & 13 & & 61 & & 39 & & 15 & & 5 & & & 47 & \\
\hline 1770 & & 62 & 29 & 26 & 8 & 24 & & & 61 & & & & & 16 & 4 & 8 & & & \\
\hline
\end{tabular}

